\title{
Recent Advances in Power-to-X Technology for the Production of Fuels and Chemicals
}

\section{Bruna Rego de Vasconcelos* and Jean-Michel Lavoie}

Biomass Technology Laboratory (BTL), Department of Chemical and Biotechnological Engineering, Université de Sherbrooke, Sherbrooke, QC, Canada

Environmental issues related to greenhouse gas emissions are progressively pushing the transition toward fossil-free energy scenario, in which renewable energies such as solar and wind power will unavoidably play a key role. However, for this transition to succeed, significant issues related to renewable energy storage have to be addressed. Power-to- $X$ $(\mathrm{PtX})$ technologies have gained increased attention since they actually convert renewable electricity to chemicals and fuels that can be more easily stored and transported. $\mathrm{H}_{2}$ production through water electrolysis is a promising approach since it leads to the production of a sustainable fuel that can be used directly in hydrogen fuel cells or to reduce carbon dioxide $\left(\mathrm{CO}_{2}\right)$ in chemicals and fuels compatible with the existing infrastructure for production and transportation. $\mathrm{CO}_{2}$ electrochemical reduction is also an interesting approach, allowing the direct conversion of $\mathrm{CO}_{2}$ into value-added products using renewable electricity. In this review, attention will be given to technologies for sustainable $\mathrm{H}_{2}$ production, focusing on water electrolysis using renewable energy as well as on its remaining challenges for large scale production and integration with other technologies. Furthermore, recent advances on PtX technologies for the production of key chemicals (formic acid, formaldehyde, methanol and methane) and fuels (gasoline, diesel and jet fuel) will also be discussed with focus on two main pathways: $\mathrm{CO}_{2}$ hydrogenation and $\mathrm{CO}_{2}$ electrochemical reduction.

Keywords: Power-to-X, renewable electricity, chemical storage, $\mathrm{CO}_{2}$ electrochemical reduction, $\mathrm{CO}_{2}$ hydrogenation

\section{INTRODUCTION}

After COP21, most countries on the planet decided to commit to act on their Green House Gases (GHG) emissions in order to cope for the possible threats that could represent climate changes. From all nations around the world, a small handful decided not to pledge specific reductions or control over their emissions up to $2030^{1}$. However, reducing GHG (Table 1) may represent a far more ambiguous challenge than it seems because of the significant consumption of energy that is being made. In addition, such tendency is actually increasing proportionally with the portion of the globe's population reaching for the middle class (Dulal et al., 2011).

Energy is considered one of the most important fundamental requirement for human survival and therefore, making this transition represents colossal modifications in our systems (The European Commission Directorate General for Energy, 2013; Overland, 2016). Energy is used to

\footnotetext{
${ }^{1}$ https://treaties.un.org/pages/ViewDetails.aspx?src=TREATY\&mtdsg_no=XXVII-7-d\&chapter=27\&lang=en
} 
TABLE 1 | List of acronyms.

\begin{tabular}{ll}
\hline GHG & Greenhouse gases \\
AC & Activated carbon \\
AEL & Alkaline electrolysis \\
ATR & Autothermal reforming \\
BDD & Boron-doped diamond \\
DME & Dimethyl ether \\
DMF & Dimethylformamide \\
EV & Electrical vehicles \\
FT & Fischer-Tropsch \\
GDE & Gas diffusion electrodes \\
HER & Hydrogen evolution reaction \\
MECS & Microbial electrolysis cells \\
MeOH & Methanol \\
MFCs & Microbial fuel cells \\
MWCNTS & Multi wall carbon nanotubes \\
NCF & Nanoporous Cu film \\
NHE & Normal hydrogen electrode \\
NOX & Nitrogen oxydes \\
NPS & Nanoparticles \\
NTS & Nanotubes \\
PEM & Polymer electrolyte membrane electrolysis \\
PES & Polyethersulfone \\
POX & Partial oxidation \\
PPS & Polyphenylene sulfide \\
PTFE & Polytetrafluoroethylene \\
PtM & Power-to-Methane \\
PtL & Power-to-Liquids \\
PtX & Power-to-X \\
PV & Photovoltaic panels \\
RHE & Reversible hydrogen electrode \\
SCE & Saturated calomel electrode \\
SMR & Steam methane reforming \\
SNG & Substitute natural gas \\
SOEC & Solid oxide electrolysis \\
TOF & Turnover frequency \\
TON & Turnover number \\
WT & \\
& Wind turbs \\
\hline
\end{tabular}

produce electricity, heat, cold, and a large amount of it is used as well for transportation, ranging from individual cars to planes, trains and boats (Thorin, 2014).

When specifically aiming at transportation fuels, the world demand is absolutely gigantic (2.5 billion tons of oil equivalent) (BP Energy Economics, 2018) although options are available and increasingly implemented around the world. In countries where green electricity is abundant (such as in some portions of Canada, namely Quebec), the opportunity for implementation of a larger pool of electric vehicles certainly has advantages (Ministère des Transports du Québec, 2015). Electric vehicles (EV) however, are still constrained by their capacities, limiting their widespread distribution in locations where population is largely distributed on a wide territory (Egbue and Long, 2012; Quak et al., 2016; Vassileva and Campillo, 2017). Other initiatives can include the production of biofuels from renewable carbon sources or biofuels. The latter are usually classified in three different "generations" where the first generally involves the utilization of ethanol (produced from grain or sugar-rich plants) as oxygenate in gasoline and fatty acid methyl ester (biodiesel) as a partial replacement for diesel (Alalwan et al., 2019). The second generation is usually related to the utilization of non-edible sugars (such as cellulose) as a sugar source to replace the contested first-generation feedstocks (Alalwan et al., 2019). Significant efforts have also been dedicated in converting all sorts of residual carbon sources such as waste plastics, MSW, residual agricultural and residual forest biomass to alkanes through techniques such as pyrolysis, gasification and liquefaction which all share their opportunities and challenges (Corma et al., 2011; Galadima and Muraza, 2015; Das and Tiwari, 2018; Kassargy et al., 2018). While it might be challenging for one of the previously mentioned option to cope for all the demand in transportation over the next decade, combining different opportunities may lead to good results and in term significantly reduce GHG emissions. Natural gas (NG) also represents a finite opportunity for the transportation sector since natural gas could represent a significant source of carbon (Fortis, 2018; Rego de Vasconcelos and Lavoie, 2018; Thiruvengadam et al., 2018) although the latter is still fossil based it is generally considered as a more sustainable option than classical oil (Rego de Vasconcelos and Lavoie, 2018; Thiruvengadam et al., 2018) and could share part of demand in a nearby future. NG can be used directly in some engine or can be transformed to gasoline, diesel and jet fuel through reforming and Fischer-Tropsch synthesis.

Transitioning from classical electricity production to sustainable models also represents its share of challenges (Lazkano et al., 2017). In opposition to traditional approaches such as nuclear, gas or coal power, renewable electricity production system such as photovoltaic panels (PV) and wind turbines (WT) is constrained by the alternating flux of electricity produced. While the production is optimal during some peak periods, the latter don't often fit with the demand, which makes of relying on these sole options a rather risky option, especially if such sustainable options are to be implemented in large cities. Other sources of renewable electricity such as hydroelectricity represents a never-ending flow of current and in some specific cases (such as in Quebec, Canada), the quantity of green electricity produced exceed the local demand which could eventually represent opportunities for other locations ${ }^{2}$. However, transportation of electricity over large distances is actually costly in light of the significant losses that are encountered over long distances ${ }^{2,3}$. In addition, some of the production facilities generating this renewable electricity are already in remote locations on the globe, which in turn involves significant losses as a starter. Hence, green electricity, either flowing or peaking, is constrained by storage, which has become over the years a significant source of concern for industry and governments, unavoidably transferring to academia (Lazkano et al., 2017).

\footnotetext{
${ }^{2}$ https://www.cbc.ca/news/canada/where-canada-s-surplus-energy-goes- 1 . 1109321

${ }^{3}$ http://www.betaengineering.com/high-voltage-industry-blog/transmittingelectricity-at-high-voltages
} 
Mechanical storage of electricity has been known for decades and options as simple as using peak energy to pump water in an elevated basin to release it during peak hours have been investigated and even implemented (Steinmann, 2017). Such options, although simple, requires a suitable landscape as well as being criticized for their efficiency (Steinmann, 2017). Batteries are also widely spread across the globe and are omnipresent in our lives going from cell phones to computer and of course, electric cars (Huang, 2018). Although originating from a historical technology, battery have been improving over the years both on efficiency and size, without forgetting their price, which is still accessible to the average consumers (Child et al., 2018). It goes without saying that batteries will have their place in the upcoming mixed-energy system where we are heading, however some of the best technologies actually on the market relies on lithium ions which in turn still represents a finite element (Child et al., 2018; Huang, 2018). Recuperation of ion has become a major concern in this field (Huang, 2018) although still far from solving another big challenge, which would be to produce a battery big enough to sustain a full large-scale city (Tervo et al., 2018).

Batteries allow the conversion of electrical energy toward chemical energy, playing on the redox functionalities of ions in solution. However, other opportunities do exist for chemical storage of renewable energy and are now referred as Power-to-X technologies (Sternberg and Bardow, 2015; Vázquez et al., 2018). As the name implies, the concept evolves around converting power (electricity) to chemicals (X), which could be very diversified hence the utilization of the "X." The most well-known technology for the production of chemicals out of electricity is water electrolysis producing hydrogen and oxygen. Hydrogen produced through electrolysis has been acclaimed as one of the optimally sustainable fuel since its combustion leads only to the production of water, which involves minimal impact on GHG emissions (Carmo et al., 2013; Buttler and Spliethoff, 2018; Chi and $\mathrm{Yu}, 2018$ ). Production of hydrogen through electrolysis is still limited in many cases by issues related to cost and storage (Carmo et al., 2013; Buttler and Spliethoff, 2018; Chi and $\mathrm{Yu}, 2018)$.

PtX technologies can also involve carbon-based structures which would make them more compatible to the existing infrastructure both for transportation and for large-scale energy production. One especially abundant carbon-based feedstock suitable for PtX technologies is carbon dioxide $\left(\mathrm{CO}_{2}\right)$, which in turn is also the actual focus of the worldwide climate change efforts (Sternberg and Bardow, 2015; Vázquez et al., 2018). Using electrocatalytic systems or through the utilization of hydrogen as reducing agent, $\mathrm{CO}_{2}$ can now be used for the production of simple $C_{1}$ molecules such as methanol (Frese, 1991; Bellotti et al., 2017) and methane (Manthiram et al., 2014; Stangeland et al., 2017). Reports from open literature shows as well that PtX technologies could eventually lead to the production of gasoline (Wei et al., 2017), diesel (Han et al., 2017), and even jet fuel (Schmidt et al., 2016). Hence, these technologies would at the same time allow storage of renewable energy, while reducing carbon dioxide emissions at the source AND producing liquid transportation fuels.
In this work, the different advances in Power-to-X technologies are investigated and discussed involving both situations where electricity is used directly to reduce carbon dioxide to chemicals up to technologies relying on the utilization of hydrogen for the reduction of carbon dioxide into a commodity that would be easier to implement into the existing worldwide infrastructure. Despite the fact that these technologies in some cases may not be entirely competitive with classical fossil fuels, they still represent an unavoidable pathway toward sustainability and only by promoting the development of these technologies can we ever hope to balance the impact of our society on the environment. The following sections will present the recent advances in the technologies for hydrogen production from renewable energy as well as the developments in the production of key chemicals, such as formic acid, formaldehyde, methanol, methane, and alkanes via Power-to-X technology.

\section{HYDROGEN}

Hydrogen $\left(\mathrm{H}_{2}\right)$ is a key element for the production of valueadded products such as methanol, formic acid, formaldehyde and liquid fuels out of $\mathrm{CO}_{2}$. Methane can also be used to the same purpose. However, using $\mathrm{H}_{2}$ would be preferable from an economical point of view since it allows the direct production of chemical and fuels, in opposition to $\mathrm{CH}_{4}$, which allows the production of syngas (Kondratenko et al., 2013). $\mathrm{H}_{2}$ is also an important and versatile energy vector with a low heating value (LHV) of $119.9 \mathrm{MJ} / \mathrm{kg}$, which is more than two times higher than the LHV of methane (Baykara, 2018).

This molecule is not available in pure state in the environment and requires to be synthesized. The main pathway currently employed at industrial scale for hydrogen production is a wellestablished process called steam methane reforming (SMR) in which natural gas (or other fossil fuel) is reacted at high temperature $\left(>700^{\circ} \mathrm{C}\right)$ with water vapor to produce hydrogen in the presence of a metal-based catalyst (Equation 1) (FerreiraAparicio et al., 2005). This process has a conversion efficiency range of 65-75\% (Abdalla et al., 2018; Baykara, 2018).

$$
\mathrm{CH}_{4}+\mathrm{H}_{2} \mathrm{O} \rightleftarrows \mathrm{CO}+3 \mathrm{H}_{2} \quad \Delta \mathrm{H}_{298 \mathrm{~K}}=206 \mathrm{~kJ} / \mathrm{mol}
$$

Partial oxidation (POX) and autothermal reforming (ATR) are also processes used for hydrogen production from fossil fuels. In the POX process, hydrocarbons are reacted with steam and oxygen at varying concentrations to produce hydrogen (Equation 2). In opposition to SMR, such technology can be operated without a catalyst. However, very high temperatures are required $\left(>1000^{\circ} \mathrm{C}\right)$ in order to get a hydrocarbon conversion. Also, a lower $\mathrm{H}_{2} / \mathrm{CO}$ around 2 is obtained. This process has been reported to have an efficiency around 50\% (Baykara, 2018).

$$
\mathrm{CH}_{4}+\frac{1}{2} \mathrm{O}_{2} \rightleftarrows \mathrm{CO}+2 \mathrm{H}_{2} \quad \Delta \mathrm{H}_{298 \mathrm{~K}}=-38 \mathrm{~kJ} / \mathrm{mol}
$$

The autothermal reforming (ATR) is a combination of SMR and POX. In this process, the energy released during the POX step is used to cope to the endothermic part of the SMR step. This 
process is also operated at high temperatures generally between 950 and $1,100^{\circ} \mathrm{C}$ (Lavoie, 2014; Rego de Vasconcelos and Lavoie, 2018) and has an efficiency around 60-75\% (Abdalla et al., 2018). None of these three processes produce pure hydrogen since carbon monoxide $(\mathrm{CO})$ is also produced at a $\mathrm{H}_{2} / \mathrm{CO}$ ratio varying between 2 and 3. Thus, a second step involving a water-gas shift reaction (Equation 3) is required in order to convert the carbon monoxide into hydrogen.

$$
\mathrm{CO}+\mathrm{H}_{2} \mathrm{O} \rightleftarrows \mathrm{CO}_{2}+2 \mathrm{H}_{2} \quad \Delta \mathrm{H}_{298 \mathrm{~K}}=-41 \mathrm{~kJ} / \mathrm{mol}
$$

Hydrogen at a $97 \%$ purity can also be produced from coal gasification, where the Koppers-Totzek process is the leading technology (Baykara, 2018). In this process, a entrained flow gasifier is used to convert the carbon into a gas mixture composed of methane, hydrogen and carbon monoxide at temperatures around $1,600-1,900^{\circ} \mathrm{C}$, temperature of which usually enhances the reaction rates 4 .

The "hydrogen economy" concept, where $\mathrm{H}_{2}$ is used as an energy vector, is however not new and was first mentioned in the 70's after an oil crisis (Ball and Weeda, 2015). However, mainly due to the low price of fossil fuels along with the high costs and technical challenges related to the use of renewable resources, fossil fuels remained the primary resource for hydrogen production. During the last few years, the interest in the topic has risen again mainly due to climate change issues showing the need to develop other energy scenarios as well as to progress on materials and renewable power generation (Hansen, 2015). However, in light of the actual environmental concerns, the advantages of using $\mathrm{H}_{2}$ as energy vector is still highly dependent on how it is produced (Ball and Weeda, 2015). There are different approaches currently under investigation for the sustainable production of $\mathrm{H}_{2}$, water electrolysis being the most promising one, which will be discussed in the following section. Other approaches to sustainably produce $\mathrm{H}_{2}$ are biomass electroreforming and the use of microorganisms in a bio-electrochemical approach. Table 2 summarizes the key operational parameters as well as the main advantages and disadvantages of each technology.

\section{Water Electrolysis}

Water electrolysis is the best known electrochemical process for producing hydrogen using renewable electricity (Dincer and Zamfirescu, 2016) and it will play a crucial role on the development of the hydrogen economy and of the PtX technology since it produces high-purity hydrogen suited not only for applications, such as metallurgical, fine chemicals and aerospace industry but also for hydrogen filling stations. This technology allows onsite $\mathrm{H}_{2}$ production from renewable energy, contributing to the use of $\mathrm{H}_{2}$ as an energy storage medium (Chi and $\mathrm{Yu}, 2018$ ) as well as to the use of renewable $\mathrm{H}_{2}$ on the production of chemicals and fuels via $\mathrm{PtX}$ technology.

${ }^{4}$ https://www.britannica.com/topic/coal-utilization-122944/Gasification\# ref623926
There are three main electrolysis technologies used for hydrogen production classified according to the electrolyte (Figure 1): alkaline water electrolysis (AEL), polymer electrolyte membrane electrolysis (PEM) and solid oxide electrolysis (SOEC). AEL is already a mature technology with commercial large-scale systems. PEM systems are also commercially available but only for small scale hydrogen production while SOEC is still at prototype stage. These technologies are compared in Table 2. The following topics will briefly discuss the recent advances in each technology as well as their potential for PtX applications.

\section{Alkaline Electrolysis (AEL)}

Alkaline electrolysis is the most mature and reliable electrolysis technology and has been used at commercial MW-scale for decades with stacks currently available up to $6 \mathrm{MW}(1,400$ $\mathrm{Nm}^{3} / \mathrm{h}$ ) (Carmo et al., 2013; Götz et al., 2016). This technology relies on the use of two electrodes immersed in a liquid alkaline electrolyte, usually $\mathrm{KOH}$ or $\mathrm{NaOH}$ solution, and separated by a diaphragm, which avoids the mixture of the product gases (Figure 1). Electrons flow from the anode to the cathode, where they are consumed by $\mathrm{H}^{+}$ions to form $\mathrm{H}_{2}$. Hydroxide ions $\left(\mathrm{OH}^{-}\right)$are then transferred through the alkaline electrolyte solution from the cathode to the anode, where they are oxidized into oxygen and water (Zeng and Zhang, 2010). High purity $\mathrm{H}_{2}$ (up to 99.9\%) can be obtained with this technology (Buttler and Spliethoff, 2018). $\mathrm{O}_{2}$ is also produced with purity in the range of $99-99.8 \%$, which can be increased to $99.999 \%$ using catalytic purification (Buttler and Spliethoff, 2018). The electrolyte concentration usually varies between 25 and $30 \mathrm{wt} . \%$ for working temperatures in the range of $70-100^{\circ} \mathrm{C}$ and for typical pressures between 1 and 30 bars (Coutanceau et al., 2018). This type of electrolyser can either operate at atmospheric or high pressure, with high-pressure electrolysers operating up to 690 bar (Table 2) (Dincer and Zamfirescu, 2016). The production of pressurized hydrogen is particularly interesting due to its higher energy efficiency when compared to $\mathrm{H}_{2}$ pressurization after production, which is usually required to further use the hydrogen produced or for direct grid injection (Götz et al., 2016). According to Voitic et al. (2015), $\mathrm{H}_{2}$ needs to be compressed up to 500 bars for transportation purposes as well as filling stations. Moreover, the gas compression along with the transportation and storage of hydrogen represent a significant cost in the hydrogen production chain (Voitic et al., 2015). Nevertheless, pressurized electrolysers have lower efficiency and produce lower purity hydrogen when compared to atmospheric pressure electrolysers (Götz et al., 2016).

The main advantages of using AEL systems are the readily availability, the durability $(55,000-120,000 \mathrm{~h})$ as well as the use of mature stack components (Schmidt et al., 2017). This technology has also the advantage of low capital costs when compared to PEM and SOEC, having investments costs around 800-1,500 $€ / \mathrm{kW}$ and maintenance costs of $2-3 \%$ of the annual investment costs (Buttler and Spliethoff, 2018). Some PtG plants rely on AEL for $\mathrm{H}_{2}$ production. The Audi e-gas plant, the world's biggest PtG plant, produces $\mathrm{H}_{2}$ with three AEL with a total power of 6 
TABLE 2 | Comparison between different processes for hydrogen production.

\begin{tabular}{|c|c|c|c|c|c|c|c|c|}
\hline $\begin{array}{l}\text { Main } \\
\text { techniques }\end{array}$ & $\begin{array}{l}\text { Cell } \\
\text { voltage }\end{array}$ & $\begin{array}{l}\text { Power } \\
\text { consumption } \\
\left(\mathrm{kWh} / \mathrm{m}^{3} \mathrm{H}_{2}\right)\end{array}$ & $\begin{array}{l}\mathrm{T} \\
\left({ }^{\circ} \mathrm{C}\right)\end{array}$ & $\begin{array}{l}P_{\max } \\
\text { (bar) }\end{array}$ & $\begin{array}{l}\text { Efficiency } \\
(\%)\end{array}$ & TRL & $\begin{array}{l}\text { Advantages/ } \\
\text { Disadvantages }\end{array}$ & References \\
\hline \multicolumn{9}{|l|}{ ELECTROLYSIS } \\
\hline Alkaline & $1.8-2.4$ & $3.8-8.2$ & $<100$ & 690 & 59-79 & Commercial & $\begin{array}{l}\text { Advantages: Low cost; mature } \\
\text { technology; possible application in } \\
\text { large plant sizes } \\
\text { Disadvantages: Low current } \\
\text { density; low dynamics; } \\
\text { corrosive electrolyte }\end{array}$ & $\begin{array}{l}\text { Dincer and Zamfirescu, 2016; } \\
\text { Götz et al., 2016; Sapountzi } \\
\text { et al., 2017; Buttler and } \\
\text { Spliethoff, } 2018\end{array}$ \\
\hline PEM & $1.8-2.2$ & $4.4-7.1$ & $<150$ & 400 & $62-82$ & Commercial & $\begin{array}{l}\text { Advantages: High power density; } \\
\text { high pressure; rapid system } \\
\text { response; no corrosive substances } \\
\text { Disadvantages: high cost; fast } \\
\text { degradation of membranes }\end{array}$ & $\begin{array}{l}\text { Dincer and Zamfirescu, 2016; } \\
\text { Götz et al., 2016; Sapountzi } \\
\text { et al., 2017; Buttler and } \\
\text { Spliethoff, } 2018\end{array}$ \\
\hline SOEC & - & 3.7 & $>500$ & 30 & Up to 100 & Prototype & $\begin{array}{l}\text { Advantages: High efficiency; } \\
\text { co-electrolysis of } \mathrm{CO}_{2} \text { and steam; } \\
\text { possible integration of waste heat } \\
\text { Disadvantages: low long term cell } \\
\text { stability; not suited for } \\
\text { fluctuating systems }\end{array}$ & $\begin{array}{l}\text { Dincer and Zamfirescu, 2016; } \\
\text { Götz et al., 2016; Sapountzi } \\
\text { et al., 2017; Buttler and } \\
\text { Spliethoff, } 2018\end{array}$ \\
\hline $\begin{array}{l}\text { Microbial } \\
\text { electrolysis }\end{array}$ & 0.2 & - & $<55$ & $P_{\text {atm }}$ & - & Laboratory & $\begin{array}{l}\text { Advantages: Use of organic waste } \\
\text { as substrate; low } \\
\text { energy consumption } \\
\text { Disadvantages: design of efficient } \\
\text { and scalable prototypes }\end{array}$ & $\begin{array}{l}\text { Hu et al., 2008; Azwar et al., } \\
2014\end{array}$ \\
\hline $\begin{array}{l}\text { Biomass } \\
\text { electro-reforming }\end{array}$ & $<1$ & $<2.4$ & $<100$ & $P_{\text {atm }}$ & - & Laboratory & $\begin{array}{l}\text { Advantages: Flexible feedstock; } \\
\text { low energy demand } \\
\text { Disadvantages: Low calorific value } \\
\text { of biomass }\end{array}$ & $\begin{array}{l}\text { Baykara, 2018; Coutanceau } \\
\text { et al., } 2018\end{array}$ \\
\hline
\end{tabular}

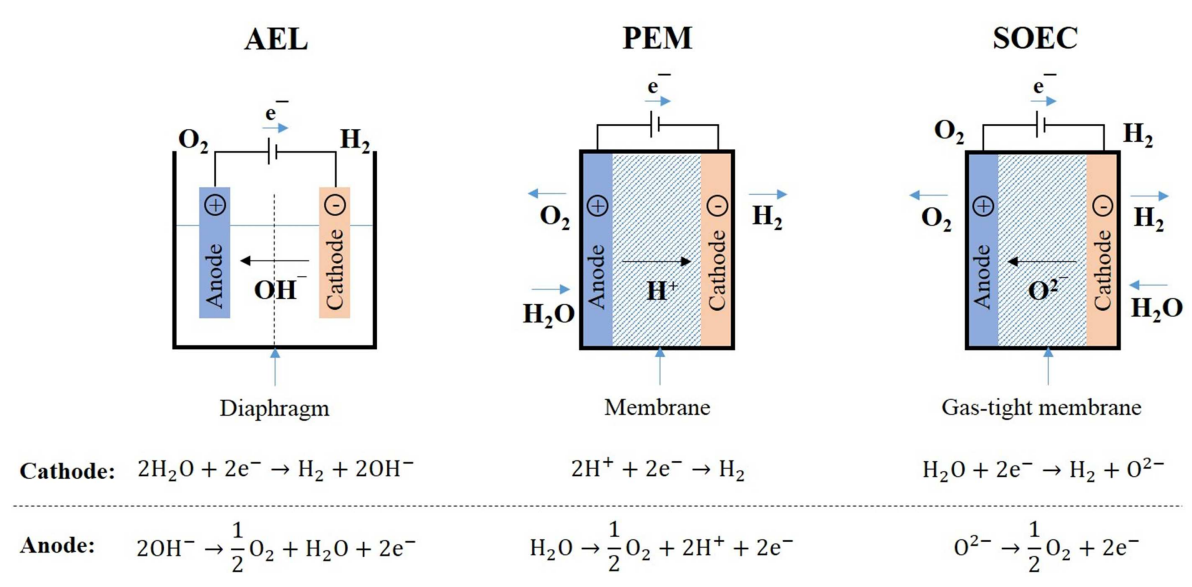

FIGURE 1 | Technologies for water electrolysis.

MW $^{5}$ (Lambert, 2018). Similarly, the BioCatProject, which is a partnership between companies, such as Electrochaea, Audi and Hydrogenics, is currently developing a PtG plant using a $1 \mathrm{MW}$ AEL electrolyser for $\mathrm{H}_{2}$ production ${ }^{6}$ (Götz et al., 2016).

Despite being a well-stablished technology, AEL has a few drawbacks, such as low partial load range and limited

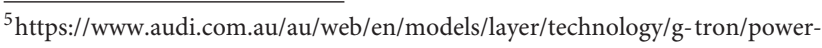
to-gas-plant.html

${ }^{6}$ http://biocat-project.com/
}

current density, which have a negative impact on the hydrogen production costs (Carmo et al., 2013; Schmidt et al., 2017). AEL electrolysers also have a limited dynamic operation, which renders them difficult to adapt to variable renewable energy sources, such as solar and wind power (Chi and $\mathrm{Yu}, 2018$ ) and decrease the system efficiency as well as the gas purity (Schmidt et al., 2017).

Recent studies on AEL electrolysis have mainly focused on the development of new diaphragm and electrode materials to improve the performance of the system (Coutanceau 
et al., 2018). The development of new diaphragm materials have taken into consideration features, such as performance, cost and health hazard (Ohmori et al., 2007). Asbestos was initially used as diaphragm. However, it has been replaced by other materials, such as polytetrafluoroethylene (PTFE), reinforced polyethersulfone (PES) membranes, glass reinforced polyphenylene sulfide (PPS) compounds, nickel oxide layer on a mesh with titatinum oxide and potassium titanate, especially due to its health risks (Rashid et al., 2015; Coutanceau et al., 2018). The electrode shape, composition and electronic properties have also been studied aiming to enhance and stabilize the electrode activity. Modifications on the electrode surface, such as addition of slits and holes, have shown to help the dissemination of gas bubbles, which are one of the major causes for extra ohmic losses (Zeng and Zhang, 2010). Nickel is the most used electrode material due to its high activity and stability in alkaline media and it has been used in commercial systems (Zeng and Zhang, 2010; Coutanceau et al., 2018). Addition of iron has proved to increase the stability of nickel electrodes by preventing the formation of nickel hydride phase at the surface of the electrode. Noble metals, such as platinum $(\mathrm{Pt})$ and ruthenium $(\mathrm{Ru})$ are also used as electrocatalysts and are known to improve the activity for the oxygen evolution reaction (Zeng and Zhang, 2010). In summary, the electrode activity can be improved by using different transition and/or noble metals as well as alloys and physical modifications of the electrode can improve gas removal and decrease the ohmic losses. Further studies are still required to reduce the overpotential of the two half reactions, to improve the electron and ionic transfer as well as to reduce the ohmic losses.

\section{Polymer Electrolyte Membrane Electrolysis (PEM)}

In this type of electrolyser, the two half-cells are separated by a proton exchange membrane, often made of Nafion polymer (Figure 1). Water is split into oxygen $\left(\mathrm{O}_{2}\right)$, protons $\left(\mathrm{H}^{+}\right)$, and electrons. $\mathrm{H}^{+}$are then transferred from the anode to the cathode through the proton exchange membrane and electrons flow from the anode to the cathode via external direct current (DC) power source. Protons and electrons then recombine at the cathode to produce hydrogen $\left(\mathrm{H}_{2}\right)$ (Martinson et al., 2014). The polymer electrolyte membrane has the role of lowering the gas crossover, providing high proton conductivity and allowing high pressure operations as well as Faraday efficiency close to 100\% (Carmo et al., 2013; Ogawa et al., 2018). Since the gas crossover is limited in this type of electrolyser, high purity hydrogen can be produced. Using proton exchange membranes instead of liquid electrolytes allows a quick response to the power input and hence the use of a wide range of power input (Carmo et al., 2013). The systems are usually operated at temperatures lower than $150^{\circ} \mathrm{C}$ and with typical pressures between 20 and 50 bar (Table 2). High pressure systems can work up to 400 bar (Dincer and Zamfirescu, 2016). This technology has become very promising for $\mathrm{H}_{2}$ production due to its compact design, high efficiency and high $\mathrm{H}_{2}$ output pressure (Chi and $\mathrm{Yu}, 2018)$. It also provides a better coupling with intermittent systems as compared to AEL and SOEC technologies (Götz et al.,
2016), making it a good candidate for PtX applications. Due to the its potential, companies, such as Siemens, Proton OnSite, Hydrogenics, AREVA $\mathrm{H}_{2}$ Gen etc., have invested in development of this technology (Bessarabov and Millet, 2018). A recent joint venture between Enbridge and Hydrogenics has taken this technology one step further in a 2.5 MW Power-to-Gas facility. The Markham Energy Storage facility built in Canada uses a 1.25 MW PEM electrolyser to produce $\mathrm{H}_{2}$ that can further be stored, shipped directly to refueling stations or to industrial and commercial customers ${ }^{7}$ (Core, 2018). Air Liquide has also recently announced the construction in Canada of a $20 \mathrm{MW}$ PEM electrolyser for zero-carbon hydrogen production using Hydrogenics technology. This unit will be the world's largest PEM electrolyser ${ }^{8}$.

The major drawbacks of this technology are related to the high costs of materials and components that need to resist the low $\mathrm{pH}$ conditions as well as the high over voltages (Carmo et al., 2013). These conditions lead to the use of expensive titanium-based components as well as of noble metals-based electrocatalysts, such as platinum and iridium (Götz et al., 2016; Chi and Yu, 2018). According to Buttler and Spliethoff (2018), investment costs for these systems vary between 1,400 and 2,100 $€ / \mathrm{kW}$ while the maintenance costs represent $3-5 \%$ of the annual investment costs.

Literature on PEM electrolysis is not abundant. However, the possibility of coupling this technology to intermittent renewable energy has led to an increase of the number of studies in the topic, which have focused on the reduction of the high costs related to this technology and more specifically on the design and synthesis of electrocatalysts. Few studies have also focused on the improvement of materials for current collectors and separator plates (Carmo et al., 2013). The replacement of noble metals-based electrocatalysts as well as decreasing the noble metal content are approaches current under investigation. Transition metals-based materials, such as molybdenum sulfide, cobalt sulfide, nickel-molybdenum alloys, iron, and cobalt phosphates etc., have been investigated as promising low cost alternatives to noble metals electrocatalysts (Di Giovanni et al., 2016). Addition of low cost oxides, such as $\mathrm{SnO}_{2}, \mathrm{Nb}_{2} \mathrm{O}_{5}$, and $\mathrm{TiO}_{2}$ to noble metals-based electrocatalysts, such as $\mathrm{IrO}_{2}$ and $\mathrm{RuO}_{2}$, has also been reported aiming to reduce the noble metal loading while maintaining similar catalytic and electronic conductivity properties (Datta et al., 2013). Finally, different synthesis methods have also being investigated to enhance the catalysts performance as well as to reduce the precious metal loading (Chourashiya and Urakawa, 2017). In summary, in order to this technology to achieve large scale, challenges related to the use of expensive catalysts and to low corrosion resistance and high cost collector and separator plates still need to be overcome (Carmo et al., 2013).

\footnotetext{
${ }^{7}$ https://www.hydrogenics.com/2018/07/16/north-americas-first-multimegawatt-power-to-gas-facility-begins-operations/

${ }^{8}$ https://industry.airliquide.ca/air-liquide-invests-worlds-largest-membranebased-electrolyzer-develop-its-carbon-free-hydrogen
} 


\section{Solid Oxide Electrolysis (SOEC)}

In this technology, the solid oxide electrolysis cell operates at high temperatures $\left(700-1,000^{\circ} \mathrm{C}\right)$, reducing the equilibrium cell voltage and thus the electricity demand to lower than 4 $\mathrm{kWh} / \mathrm{Nm}^{3} \mathrm{H}_{2}$ (Table 2) (Götz et al., 2016). SOEC electrolysis is in fact the reverse process occurring in a fuel cell (Hansen, 2015), where $\mathrm{H}_{2} \mathrm{O}$ (steam) reacts at the cathode with electrons from an external power source, producing $\mathrm{H}_{2}$ and oxygen ions which are transported through a gas-tight membrane to the anode, where oxygen ions combine to form $\mathrm{O}_{2}$ and liberate electrons (Figure 1). Hydrogen is produced in this process at high Faraday efficiency around 100\% (Ogawa et al., 2018). Another advantage of this technology is the possibility of heat integration with exothermic processes, such as methanol production. Heat released from these processes can be used to heat the steam to the temperature of the SOEC process (Buttler and Spliethoff, 2018). SOEC systems also offer the possibility of flexible operation between electrolysis and fuel cells. Since $\mathrm{H}_{2}$ produced through this process could be later reconverted in electricity using a fuel cell, this technology could represent an opportunity to store renewable electricity surplus generated by wind or solar power, for example. SOEC also presents the capacity of co-electrolysis of $\mathrm{CO}_{2}$ and steam for syngas production, which can be later converted into value-added products, such as liquid fuels. This capacity of co-electrolysis renders this technology very attractive for Power-to-X applications.

Contrarily to AEL and PEM, which are already at commercial level, SOEC is still at prototype stage and parameters, such as lifetime, cycling stability and pressurized operation still need to be validated (Buttler and Spliethoff, 2018). The major drawbacks preventing this technology from reaching large scale is the fast material degradation and thus low stability (Buttler and Spliethoff, 2018) related to the high temperature used and to long-term operation. Studies have proven that this degradation can be limited when the current density is low $\left(<1 \mathrm{Acm}^{-2}\right)$. Hence, recent studies have focused on improving the stability of materials at high current densities (Ogawa et al., 2018).

Electrode materials must be ionic and electronic conducting in order to facilitate electron and mass transport as well as to allow the migration of $\mathrm{O}^{2-}$ species (Coutanceau et al., 2018; Arunkumar et al., 2019). In general, electrode materials consist of mixed oxides with perovskite structure. Ni-YSZ (yttriastabilized zirconia) and LSM (lanthanum strontium manganite) are the most used materials for cathode and anode, respectively (Moçoteguy and Brisse, 2013; Ogawa et al., 2018). LSM has a coefficient of thermal expansion close to the one of the electrolyte, stabilizing the electrolysis cell. Moreover, LSM has very low chemical reactivity with YSZ, increasing the lifetime of the material (Moçoteguy and Brisse, 2013). Double perovskites, fluorites and metals have also been studied (Arunkumar et al., 2019). Mixing different oxides at different amounts has shown to improve activity and stability of the materials. Adding $\mathrm{Co}_{3} \mathrm{O}_{4}$ to LSM-BCZYZ, for example, significantly improve the electrode processes and enhances the current density under a certain voltage ( $\mathrm{Li}$ et al., 2013). Mixed ion-electron conducting electrodes, such as lanthanum strontium copper ferrite and lanthanum strontium cobalt ferrite have also been used to improve the ionic conductivity property of electrodes (Moçoteguy and Brisse, 2013).

Electrolytes are generally composed by zirconia-based materials doped with $\mathrm{CaO}, \mathrm{MgO}, \mathrm{Sc}_{2} \mathrm{O}_{3}$ as well as rare-earth oxides. However, the most used electrolyte is yttria-stabilized zirconia (YSZ) due to its good ionic conductivity and mechanical properties (Hansen, 2015). $\mathrm{La}_{1-\mathrm{x}} \mathrm{Sr}_{\mathrm{x}} \mathrm{Ga}_{1-\mathrm{y}} \mathrm{Mg}_{\mathrm{y}} \mathrm{O}_{2.85}$ (LSGM) has been identified as a promising electrolyte material due to its high ion conductivity that can be five times higher than that of classical YSZ. However, further investigation is still needed to prove the durability of this material (Moçoteguy and Brisse, 2013).

The flexibility regarding the operation mode of this technology, the possibility of $\mathrm{CO}_{2}$ and steam co-electrolysis as well as the higher energy efficiency of SOEC when compared to AEL and PEM has led major companies to invest in the development of SOEC. Sunfire, for example, has recently investigated this possibility by developing a SOEC module in a demonstration project at Salzgitter Flachstahl $\mathrm{GmbH}$ aiming to evaluate the potential of the module for energy balancing and load management. The module has a hydrogen production capacity of $40 \mathrm{Nm}^{3} / \mathrm{h}$ and with an input power of $150 \mathrm{~kW}$. The electrical efficiency of the system is higher than $80 \%$. The system can also be reversed into fuel cell with an output power of $30 \mathrm{~kW}$ (Berkeley, 2017). Haldor Topsoe ${ }^{9}$, Fuel Cell Energy $^{10}$ and Toshiba ${ }^{11}$ have also worked on the development of this technology.

\section{Other Approaches}

\section{Biomass Electroreforming}

Biomass electroreforming for hydrogen production has gained increased attention due to its renewable character and to the flexibility of the feedstock. Different feedstock, such as energy crops and forestry and agricultural residue, can be used. In this process, organic compounds originated from biomass, such as alcohols and sugars, are oxidized in aqueous media coproducing hydrogen in the cathode of the electrolysis cell. The advantages of this process are the use of much lower temperatures $\left(<100^{\circ} \mathrm{C}\right)$ then the classical routes (steam reforming and partial oxidation) and the production of high-purity hydrogen (Coutanceau et al., 2018). This process is also less energyintensive than traditional water electrolysis process (GutierrezGuerra et al., 2015). Gutierrez-Guerra et al. (2015) compared the performance of the electrochemical reforming of ethanol with the classical catalytic reforming of ethanol. They reported that the electrochemical reforming process provided pure hydrogen in a single step while the catalytic process required additional steps. Moreover, the energy consumption and the amount of feedstock material were lower for the electrochemical process. Caravaca et al. (2013) investigated the hydrogen production from the electrochemical reforming of a bio-ethanol/water solution at $80^{\circ} \mathrm{C}$ in a PEM electrolyser. They showed that the electrochemical reforming of bio-ethanol led to the production of

\footnotetext{
${ }^{9}$ https://blog.topsoe.com/how-can-electrolysis- of- water-help-to-produce-fuelfor-your-future-car

${ }^{10}$ https://www.fuelcellenergy.com/storage/

${ }^{11}$ https://www.toshiba-energy.com/en/hydrogen/rd/\#rd02
} 
hydrogen and that the PEM electrolyser could perform for long operation times $(6 \mathrm{~h})$.

\section{Microorganisms}

Bio-electrochemical systems use microorganisms to catalyze the oxidation-reduction reaction at the cathodes and anodes. These systems are divided into Microbial Fuel Cells (MFCs) and Microbial Electrolysis Cells (MECs). In both processes, the bacteria decompose the organic material at the anode and hydrogen is produced at the cathode. However, additional electricity is required to the MEC system in order to supress the production of methane and oxygen, which lower the selectivity to $\mathrm{H}_{2}$ (Baykara, 2018). Despite the promising aspects of this technology, the design of efficient and scalable prototypes are still pending (Azwar et al., 2014).

\section{$\mathrm{CO}_{2}$ DERIVED CHEMICALS}

PtX technologies can be used to produce value-added chemicals and fuels from $\mathrm{CO}_{2}$ through two main approaches: $\mathrm{CO}_{2}$ hydrogenation (Figure 2) and $\mathrm{CO}_{2}$ electrochemical reduction (Figure 3).

$\mathrm{CO}_{2}$ hydrogenation process (Figure 2) is performed in two steps, first of which, $\mathrm{H}_{2}$ is produced using renewable energies, such as solar, wind and hydro through process, such as water electrolysis. In the second step, the $\mathrm{H}_{2}$ produced is used to convert the $\mathrm{CO}_{2}$ issued from industrial processes or power plants, for example. This approach has gained increased attention due to its fast kinetics when compared to other approaches such as electrocatalysis and photocatalysis, and to its flexibility (Li et al., 2018b). However, this technology still faces some challenges, in particular the sustainable hydrogen production. As presented in the section Water Electrolysis, water electrolysis is the main technology investigated for sustainable hydrogen production. However, improvements in efficiency and cost reduction are still required to overcome technical and economic barriers to its commercialization (Götz et al., 2016). Finally, integration of the different steps of the technology $\left(\mathrm{CO}_{2}\right.$ capture, water electrolysis and $\mathrm{CO}_{2}$ hydrogenation) is also still an issue.

$\mathrm{CO}_{2}$ electrochemical reduction (Figure 3) is a more recent and less advanced approach when compared to $\mathrm{CO}_{2}$ hydrogenation. In this process, $\mathrm{CO}_{2}$ reduction is connected to an oxidation reaction (usually the water oxidation), where water is oxidized in $\mathrm{O}_{2}$, protons $\left(\mathrm{H}^{+}\right)$and electrons $\left(\mathrm{e}^{-}\right)$at the anode. Then, the electrons flow to the cathode where they combine with $\mathrm{CO}_{2}$ to form different reduced products, such as methanol, methane and formic acid. In this case, renewable electricity is used to convert $\mathrm{CO}_{2}$ directly into fuels and chemicals, which represents a great potential for renewable energy storage and for lowering the GHG emissions into the atmosphere. In addition to its environmental advantages, the electrochemical reduction of $\mathrm{CO}_{2}$ can be performed at ambient temperature and pressure and can lead to the desired products only by adjusting some parameters such as the electrocatalyst, the operating potential and the electrolyte (Zhang and Zhang, 2017). Furthermore, the systems used with this processes are compact and could easily be scaled-up (Chen and Liu, 2018), leading the technology close to the demonstration phase (Reis Machado and Nunes da Ponte, 2018). However, considerable challenges such as high overpotentials, the slow kinetics of $\mathrm{CO}_{2}$ electroreduction, and poor product selectivity could slow down the use this technology at large scale (Kortlever et al., 2015; Chen and Liu, 2018). In addition, the direct electrochemical reduction of $\mathrm{CO}_{2}$ generates many different products, depending mainly on the reaction medium and on the catalyst (Albo et al., 2015). Hence, the development of electrocatalysts, allowing an efficient and selective reduction of the $\mathrm{CO}_{2}$ is essential for the development of this technology at large scale.

Among the many useful chemicals that can be synthesized directly from $\mathrm{CO}_{2}$, methane, methanol, alkanes, formic acid and formaldehyde, have a strategic use in the chemical industry, either as platform chemicals and/or for the production/storage of energy. The following topics intend to investigate the recent advances in the synthesis of the chemicals using both $\mathrm{CO}_{2}$ hydrogenation and $\mathrm{CO}_{2}$ electrocatalytically reduction.

\section{Formic Acid}

Formic acid $(\mathrm{HCOOH})$ is one of the main products that can be produced from $\mathrm{CO}_{2}$ reduction having a market value around 500-900 US\$/mt HCOOH (Huang et al., 2018) as well, it is considered as a $\mathrm{C}_{1}$ building block and can also be used as a fuel in formic acid fuels cells (DFAFCs) (Mura et al., 2012; Kortlever et al., 2015; Huang et al., 2018). Its production is expected to reach $760 \mathrm{Mt}$ by 2019 (Huang et al., 2018). Formic acid is also considered as one of the most promising and safest liquid hydrogen carriers (Onishi et al., 2018) with a hydrogen content of $52 \mathrm{~g} / \mathrm{L}$, whose release from formic acid is favored at room temperature $\left(\Delta G^{\circ}=-32.8 \mathrm{~kJ} / \mathrm{mol}\right.$ ) (Singh et al., 2016). The most common industrial process for formic acid production involves a two-step process, in which methyl formate is synthesized from methanol and carbon monoxide in the first step (Equation 4) and then, methyl formate is hydrolyzed into formic acid in the second step (Equation 5) (Singh et al., 2016; Huang et al., 2018). However, production of formic acid in the second step is not thermodynamically favorable.

$$
\begin{aligned}
\mathrm{CH}_{3} \mathrm{OH}+\mathrm{CO} \rightleftarrows \mathrm{CH}_{3} \mathrm{COOH} \quad \Delta \mathrm{H}_{\mathrm{r}}=-29 \mathrm{~kJ} / \mathrm{mol} \\
\mathrm{CH}_{3} \mathrm{COOH}+\mathrm{H}_{2} \mathrm{O} \rightleftarrows \mathrm{HCO}_{2} \mathrm{H}+\mathrm{CH}_{3} \mathrm{OH} \quad \Delta \mathrm{H}_{\mathrm{r}}=+16.3 \mathrm{~kJ} / \mathrm{mol}
\end{aligned}
$$

Formic acid can also be chemically synthesized by several other processes, such as oxidation of biomass, $\mathrm{CO}_{2}$ hydrogenation, $\mathrm{CO}_{2}$ electrochemical reduction, $\mathrm{CO}_{2}$ reduction by biocatalysts and also as a by-product of acetic acid production (Singh et al., 2016). This review will focus only on $\mathrm{CO}_{2}$ hydrogenation and on the $\mathrm{CO}_{2}$ electrochemical reduction.

\section{$\mathrm{CO}_{2}$ Electrochemical Reduction}

As showed in Equations (4) and (5), the equilibrium toward formic acid production is unfavorable in the classical process, leading to the investigation of other possible processes to the direct synthesis of formic acid. The electrochemical reduction of $\mathrm{CO}_{2}$ gained increased attention in the last decades due to its environmental advantages as well as its potential to directly convert $\mathrm{CO}_{2}$ into formic acid. However, as for all $\mathrm{CO}_{2}$ electrochemical reduction processes, high overpotentials and low product selectivity are the main bottlenecks for the development of this process (Reis Machado and Nunes da Ponte, 2018). 


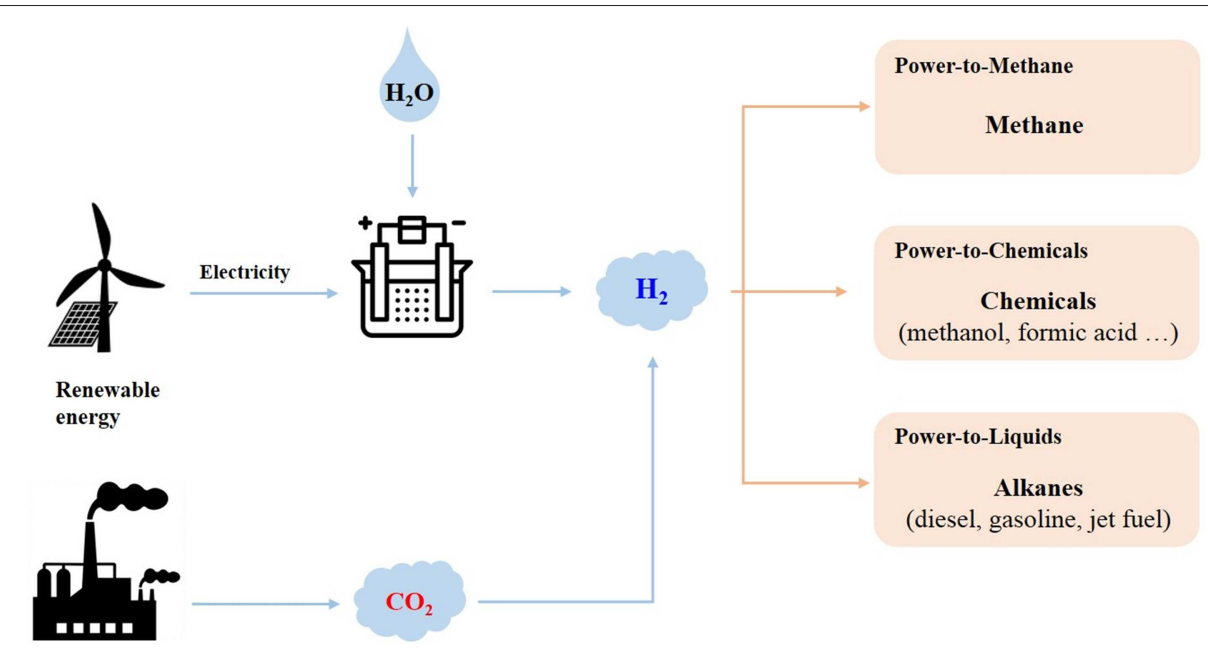

FIGURE 2 | Power-to-X via $\mathrm{CO}_{2}$ hydrogenation.

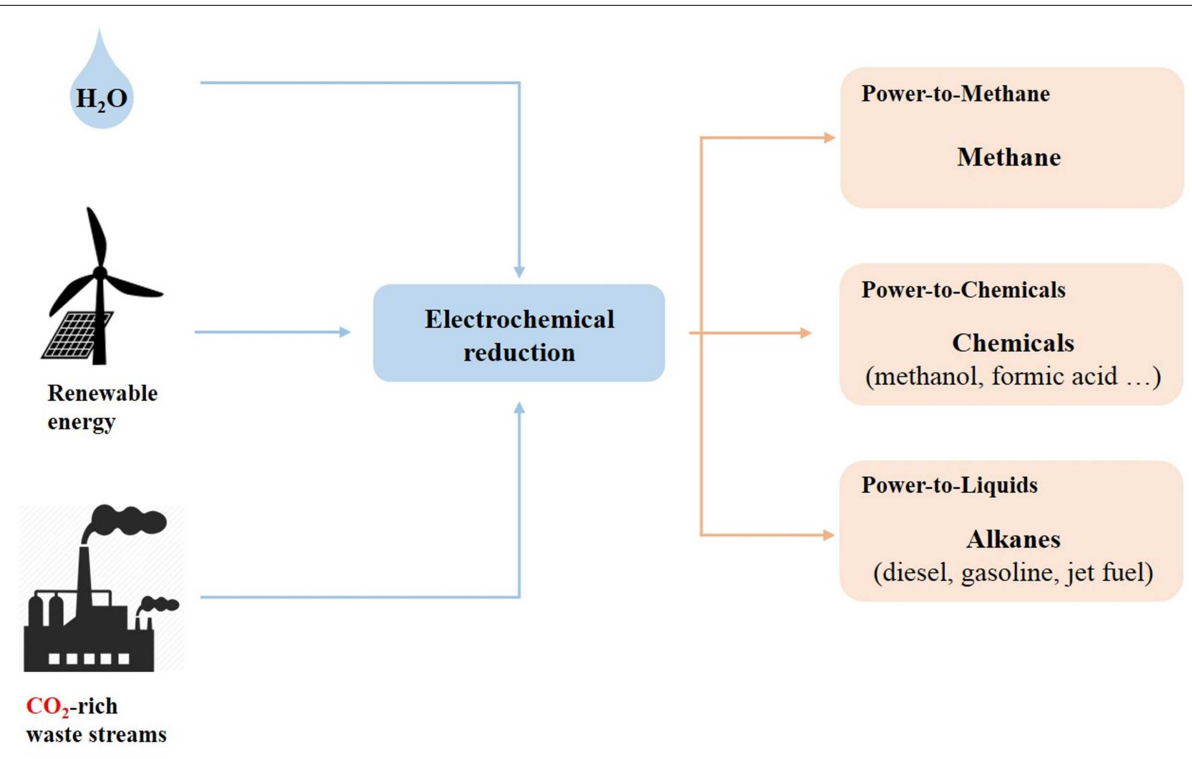

FIGURE 3 | Power-to-X via electrochemical reduction.

Thus, the development of less energy-intensive electrocatalysts is of importance to lower the overpotentials as well as to increase the selectivity to formic acid (Benson et al., 2009). Hori (2008) investigated the capability of different metals, such as $\mathrm{Pb}, \mathrm{Hg}, \mathrm{Tl}, \mathrm{In}, \mathrm{Sn}, \mathrm{Au}, \mathrm{Ag}, \mathrm{Zn}, \mathrm{Pd}, \mathrm{Ga}, \mathrm{Cu}, \mathrm{Ni}, \mathrm{Fe}, \mathrm{Pt}$, Ti to electrochemically reduce $\mathrm{CO}_{2}$ to formic acid. They found that the product distribution was deeply dependant on the metal electrodes. $\mathrm{Pb}, \mathrm{Hg}, \mathrm{Tl}, \mathrm{In}, \mathrm{Sn}, \mathrm{Cd}$, and $\mathrm{Bi}$ showed to be very efficient catalysts for the electrochemical reduction of $\mathrm{CO}_{2}$ in formic acid with Faradaic efficiencies up to $99.5 \%$. However, they required very negative overpotentials around $-2.0 \mathrm{~V}$ vs. saturated calomel electrode (SCE) to reach good product selectivity (Hori, 2008). Pt and Pd showed improved selectivity to formic acid, however, they also catalyzed the hydrogen evolution reaction (HER), a side reaction to $\mathrm{CO}_{2}$ reduction that lowers the Faradaic efficiency toward the formic acid production. $\mathrm{CO}$ poisoning is also a problem for $\mathrm{Pt}$ electrodes since the $\mathrm{CO}$ formed during the $\mathrm{CO}_{2}$ reduction covers the platinum surface, reducing the performance of the catalyst. However, Kortlever et al. (2015) reported that a palladium-platinum catalytic system reduced $\mathrm{CO}_{2}$ to formic acid using very low overpotentials, starting from $-0.05 \mathrm{~V}$ vs. reversible hydrogen electrode (RHE) at $\mathrm{pH}=6.7$. Nevertheless, the main challenge remains to avoid the $\mathrm{CO}$ poisoning. 
Since sulfur poisoning has been reported to be a considerable issue for HER catalysts it could be beneficial for competitive reactions. Thus, Huang et al. (2018) studied the influence of sulfur dopants in the performance of copper catalysts, aiming to limit the HER during $\mathrm{CO}_{2}$ electrochemical reduction to formic acid. They showed that a copper-based catalyst, doped with 2.7 wt.\% of sulfur, exhibited a formate current density 46 times higher than the undoped catalyst. The sulfur-doped catalyst showed a faradaic efficiency of $75 \%$ during $12 \mathrm{~h}$, while its structure was shown to play a role in the selectivity to formic acid. Kumar et al. (2017) evaluated the performance of Sn-based catalysts on the $\mathrm{CO}_{2}$ electrochemical reduction and they proved that a nanoporous and high-density grain boundary structure is an important factor to increase the selectivity and the rate of formic acid production from $\mathrm{CO}_{2}$ electroreduction. The $\mathrm{SnO}_{2}$ porous nanowires synthesized showed a $\mathrm{CO}_{2}$-to- $\mathrm{HCOOH}$ efficiency of $56 \%$, being one of the most performing catalysts reported for this process.

Biocatalysts have also been used for the production of formic acid from $\mathrm{CO}_{2}$ electrochemical reduction, presenting higher selectivity than conventional metal electrodes. Hwang et al. (2015) investigated the use of different Methylobacteria as a whole-cell biocatalysts for the electrochemical conversion of $\mathrm{CO}_{2}$ to formate. They found that the Methylobacterium extorquens $\mathrm{AM} 1$ had a high capability to convert $\mathrm{CO}_{2}$ by suppling electrons, producing $60 \mathrm{mM}$ of formate without requiring any additional hydrogen supply. However, the synthesis was relatively slow, taking $80 \mathrm{~h}$ to produce the $60 \mathrm{mM}$ of formate with $1.9 \mathrm{~g}$ of the catalyst. Similarly, Le et al. (2018) investigated the performance of the Shewanella oneidensis MR-1 due to it powerful electron transfer system. With an optimization of the S. oneidensis MR1 growth, up to $136.84 \mathrm{mM}$ of formate was produced after $72 \mathrm{~h}$. The reaction rate was $3.8 \mathrm{mM} \mathrm{h}^{-1} \mathrm{~g}^{-1}$, being almost 10 times faster when compared to the values previously obtained by Hwang et al. (2015).

\section{$\mathrm{CO}_{2}$ Hydrogenation}

The actual industrial process for formic acid production from methanol and carbon monoxide (Equations 4 and 5) emits around $3,100 \mathrm{~kg}$ of $\mathrm{CO}_{2}$ for each ton of formic acid produced. $\mathrm{CO}_{2}$ hydrogenation to formic acid (Equation 6) has gained increased attention since it could reduce the greenhouse gases emissions related to the formic acid production (Gunasekar Hariyanandam et al., 2016) by a 10-fold, especially if coupled with a hydrogen production process using renewable energy, such as electrolysis. Moreover, this process has become a significant milestone to consolidate formic acid as a reversible hydrogen storage carrier (Singh et al., 2016). The hydrogenation of $\mathrm{CO}_{2}$ in gas phase is not entropically favored though, since it involves the conversion of two gaseous reactants into liquid products (Wang et al., 2015; Gunasekar Hariyanandam et al., 2016). However, the reaction is favorable in aqueous medium (Equation 7).

$$
\begin{aligned}
\mathrm{CO}_{2(\mathrm{~g})}+\mathrm{H}_{2(\mathrm{~g})} & \rightleftharpoons \mathrm{HCOOH}_{(l)} \quad \Delta \mathrm{G}_{298 \mathrm{~K}}=32.8 \mathrm{~kJ} / \mathrm{mol}(6) \\
\mathrm{CO}_{2(\mathrm{aq})}+\mathrm{H}_{2(\mathrm{aq})} & \rightleftharpoons \mathrm{HCOOH}_{(a q)} \quad \Delta \mathrm{G}_{298 \mathrm{~K}}=-4 \mathrm{~kJ} / \mathrm{mol}
\end{aligned}
$$

Hence, the selection of the medium (solvents, water) is of crucial importance since it can allow for the reaction to be more thermodynamically favorable (Wang et al., 2015; Gunasekar Hariyanandam et al., 2016; Singh et al., 2016). In addition, basic additives, such as trimethylamine and ammonia are often used to shift the equilibrium toward formic acid production (Wang et al., 2015; Gunasekar Hariyanandam et al., 2016; Álvarez et al., 2017). Noble metals homogeneous catalysts are more commonly used in this process due to their promising catalytic performances. Noble metals, such as Ruthenium (Ru), Rhodium (Rd), and Iridium (Ir) have shown excellent catalytic results and transition metals, such as Nickel $(\mathrm{Ni})$, Copper $(\mathrm{Cu})$, and Iron $(\mathrm{Fe})$ have also been investigated despite their lower activity due to their lower cost compared to the nobles metals (Wang et al., 2015; Gunasekar Hariyanandam et al., 2016; Álvarez et al., 2017).

Tanaka et al. (2009) studied the performance of a Ir(III)-PNP pincer complex in aqueous $\mathrm{KOH}$ medium for the hydrogenation of $\mathrm{CO}_{2}$ to formic acid. At $120^{\circ} \mathrm{C}$ and $6 \mathrm{MPa}$, the catalyst was very performant, leading to a high TOF of $73,000 \mathrm{~h}^{-1}$ for $48 \mathrm{~h}$. They also showed that the use of a stronger base $(\mathrm{KOH}$ instead of $\mathrm{K}_{3} \mathrm{PO}_{4}$ ) could increase formic acid yield from 60 to $70 \%$, confirming the strong role of the base in the reaction. Liu et al. (2015) developed an efficient Ir complex containing imine-diphosphine ligands for $\mathrm{CO}_{2}$ hydrogenation. The catalyst exhibited a TOF of $450,000 \mathrm{~h}^{-1}$ at $140^{\circ} \mathrm{C}$ for $20 \mathrm{~h}$ in a $5 \mathrm{M}$ $\mathrm{KOH}$ medium. The catalytic performance of the Ir complex was attributed to the $C=N$ bond of the ligand that acted as an acceptor of $\mathrm{H}_{2}$ that further led to the production of formate. Munshi et al. (2002) studied the influence of different bases and alcohols on the rate of supercritical $\mathrm{CO}_{2}$ hydrogenation using $\mathrm{RuCl}(\mathrm{OAc})\left(\mathrm{PMe}_{3}\right)_{4}$, a ruthenium trimethylphosphine complex. The results revealed that the selection of the appropriate amine and alcohol have a great influence on the rate of the reaction. The use of pentafluorophenol as alcohol and triethylamine as base at $50^{\circ} \mathrm{C}$ and $19 \mathrm{MPa}$ for $20 \mathrm{~min}$ led to a TOF for formic acid production of $95,000 \mathrm{~h}^{-1}$. The pentafluorophenol alcohol, for example, could have acted either as a hydrogen donor or as a proton donor, favoring the hydrogenation reaction. To the best of our knowledge, Filonenko et al. (2014) developed a ruthenium complex catalyst that has showed the best results for formic acid production. They investigated the performance of a $\mathrm{Ru}$ PNP-pincer catalyst in a batch reactor at $120^{\circ} \mathrm{C}$ and $2.7 \mathrm{MPa}$ for $1 \mathrm{~h}$ using dimethylformamide (DMF) as solvent and 1,8diazabicyclo[5.4.0] undec-7-ene (DBU) as base and obtained a TOF for formic acid production of $1,100,000 \mathrm{~h}^{-1}$. In agreement with the finding of Tanaka et al. (2009), they stated that strong bases play an important role in this reaction by affecting the rate determining step of the reaction. When a strong base is used, the initial $\mathrm{H}_{2}$ recombination is the rate-determining step.

Despite their excellent catalytic performances for hydrogenation of $\mathrm{CO}_{2}$ into formic acid, these homogeneous catalysts are difficult to separate from the products at the end of the reaction and the amount of $\mathrm{CO}_{2}$ actually hydrogenated per unit of time is still low, hindering their use at large scale (Gunasekar Hariyanandam et al., 2016; Álvarez et al., 2017). Moreover, these homogeneous catalysts may also promote the reverse reaction, in which the formate produced 
can be transformed back into $\mathrm{CO}_{2}$ and $\mathrm{H}_{2}$ (Gunasekar Hariyanandam et al., 2016). To cope with the problematics related to homogeneous catalysts, studies were recently published on the use of heterogeneous catalysts for the hydrogenation of $\mathrm{CO}_{2}$.

Umegaki et al. (2016) were the first to study the performance of ruthenium ( $\mathrm{Ru}$ ) nanoparticles (unsupported catalyst) in the hydrogenation of supercritical $\mathrm{CO}_{2}$ into formic acid. The reaction was carried out at $353 \mathrm{~K}$ and $13 \mathrm{MPa}$ for $3 \mathrm{~h}$ in a mixture of water and trimethylamine. They observed that the metallic nanoparticles were very active and stable during the test, leading to a TOF of formic acid of $2,117 \mathrm{~h}^{-1}$. The stability of the catalyst was attributed to the fact that the nanoparticles maintained their metallic state after the test.

The influence of ruthenium-based catalysts doped on different supports, such as $\mathrm{MgO}, \mathrm{Al}_{2} \mathrm{O}_{3}$, and activated carbon $(\mathrm{AC})$ was studied by Hao et al. (2011). Each support was doped with 2 wt.\% $\mathrm{Rh}$ and the hydrogenation tests were performed at $353 \mathrm{~K}$ and 13.55 MPa in the presence of ethanol as solvent and triethylamine as base, which were added to extract the formic acid, increasing the reaction rate. The $\mathrm{Ru} / \mathrm{AC}$ and the $\mathrm{Ru} / \mathrm{Al}_{2} \mathrm{O}_{3}$ catalysts showed good catalytic performances with turnover numbers (TON) of 10 and 91, respectively. The catalytic performance of the catalysts was attributed to the presence of hydroxyl groups on the surface of the catalysts that increased the adsorption of $\mathrm{CO}_{2}$. The higher yield of formic acid obtained with the $\mathrm{Ru} / \mathrm{Al}_{2} \mathrm{O}_{3}$ catalyst compared to the $\mathrm{Ru} / \mathrm{AC}$ was in fact due to its greater number of hydroxyl groups. The $\mathrm{MgO}$ support was chosen for its strong basic sites, eliminating the need of using basic additives that need to be neutralized and separated from the product at the end of the reaction. However, no formic acid was produced in the presence of this catalyst, probably due to the absence of hydroxyl groups on its surface as well as the high $\mathrm{pH}$ of the solution that lead to the formation of inactive $\mathrm{RuO}_{2}$ species. Similarly, Zhang et al. (2018) obtained a good catalytic performance of a Rubased catalyst doped on an alumina support. They investigated the performance of the $\mathrm{Ru}-\mathrm{PPh}_{3} / \mathrm{Al}_{2} \mathrm{O}_{3}$ catalyst as well as the presence of additives and solvents in the $\mathrm{CO}_{2}$ hydrogenation to formic acid reaction in a batch reactor at $80^{\circ} \mathrm{C}$ and 12 $\mathrm{MPa}$ for $1 \mathrm{~h}$. The catalyst showed a high turnover frequency of formic acid of about $751 \mathrm{~h}^{-1}$ in a mixed solution of ethanol, triethylamine and water and in the presence of $\mathrm{KH}_{2} \mathrm{PO}_{4}$ and $\mathrm{PPh}_{3}$ as additives. They reported that the high TOF obtained was related to the use of $\mathrm{PPh}_{3}$ as proton donor, $\mathrm{KH}_{2} \mathrm{PO}_{4}$ as proton source and trimethylamine as basic additive, increasing the conversion of $\mathrm{CO}_{2}$.

$\mathrm{Su}$ et al. (2015) studied the performance of different heterogeneous palladium-based catalysts doped on different supports. In this work, all catalysts were doped with 5 wt.\% of palladium $(\mathrm{Pd})$ and the best hydrogenation results were obtained at $20^{\circ} \mathrm{C}$ for $1 \mathrm{~h}$ in a $1 \mathrm{M} \mathrm{NH}_{4} \mathrm{HCO}_{3}$ medium. They showed that the $\mathrm{CO}_{2}$ hydrogenation test performed at $2.7 \mathrm{MPa}$ with the $\mathrm{Pd} / \mathrm{Al}_{2} \mathrm{O}_{3}$ catalyst resulted in a TOF of $278 \mathrm{~h}^{-1}$ while the hydrogenation test, performed at $5.5 \mathrm{MPa}$ with the $\mathrm{Pd} / \mathrm{AC}$ (activated carbon) nanocatalyst, showed a TOF as high as 1,103 $\mathrm{h}^{-1}$. The main reasons for the difference in the performance of both catalysts was the localized higher $\mathrm{H}_{2}$ concentrations on the surface of the activated carbon-based catalysts as well as a higher $\mathrm{Pd}$ dispersion that favored the hydrogenation reaction.

\section{Formaldehyde}

Formaldehyde $\left(\mathrm{CH}_{2} \mathrm{O}\right)$ is currently used in about 50 industrial process as building block for the production of daily life products, such as paints, cosmetics, resins, polymers, plastics etc (Heim et al., 2016; Zhang et al., 2017). It is mainly produced via the energy and cost-intensive Formox process in which methanol is partially oxidized at $300-400^{\circ} \mathrm{C}$ (Equation 8) (Heim et al., 2016). Methanol used in the process is produced from syngas, which in turn is produced from steam reforming of natural gas (Heim et al., 2016). More than 35\% of the world methanol production is actually used for formaldehyde production (Heim et al., 2017). The drawbacks of this process are high temperatures and energyintensive compression and purification steps, affecting the overall economics of the process.

$\mathrm{CH}_{3} \mathrm{OH}+\frac{1}{2} \mathrm{O}_{2} \rightleftarrows \mathrm{HCHO}+\mathrm{H}_{2} \mathrm{O} \quad \Delta \mathrm{H}_{298 \mathrm{~K}}=-159 \mathrm{~kJ} / \mathrm{mol}(8)$

Since $\mathrm{CH}_{2} \mathrm{O}$ is a hydrogen-rich molecule, it has a great potential to be used as a liquid hydrogen carrier, capable of delivering high-purity $\mathrm{H}_{2}$ in a hydrogen fuel cell (Heim et al., 2017). Moreover, it could be even more interesting as liquid hydrogen carrier than methanol since formaldehyde reforming process is much less energy intensive than methanol reforming (Heim et al., 2017). However, in order to produce $\mathrm{H}_{2}$ with a low carbon footprint, formaldehyde has to be produced more sustainably. There has been recent efforts for developing new processes for sustainably producing formaldehyde, such as $\mathrm{CO}_{2}$ hydrogenation, electrochemical and enzymatic approaches. However, the literature on this subject is relatively scarce, especially when heterogeneous catalysts are considered. The main findings on the formaldehyde production via $\mathrm{CO}_{2}$ reduction will be detailed in the following sub-sections.

\section{$\mathrm{CO}_{2}$ Electrochemical Reduction}

Very few reports from the open literature related the electrochemical reduction of $\mathrm{CO}_{2}$ to formaldehyde. Nakata et al. (2014) reported the highest Faradaic efficiency to formaldehyde obtained through $\mathrm{CO}_{2}$ electroreduction up to date. The authors investigated the $\mathrm{CO}_{2}$ reduction using Boron-doped diamond (BDD) electrodes in various electrolytes, such as methanol and seawater. When seawater was used as electrolyte, relatively low formaldehyde yield of $36 \%$ was obtained due to impurities in the seawater and to the narrow potential window in water. On the other hand, a Faradaic efficiency of $75 \%$ to formaldehyde was obtained at $-1.5 \mathrm{~V}$ (vs. $\mathrm{Ag} / \mathrm{AgCl}$ ). When a glassy carbon electrode was used, a Faradaic efficiency of only $15 \%$ was obtained in the same conditions. The performance of the BDD electrodes was attributed to the presence of $\mathrm{sp}^{3}$-bonded carbon, while glassy carbon has large amounts of $\mathrm{sp}^{2}$-bonded carbon, resulting in low Faradaic efficiencies. Furthermore, BDD electrodes presented very good stability over $20 \mathrm{~h}$, while the surface of the glass carbon electrode dramatically changed after $20 \mathrm{~h}$ of electrolysis, highlighting the potential of the BDD electrodes to formaldehyde production via $\mathrm{CO}_{2}$ electrochemical reduction. 


\section{$\mathrm{CO}_{2}$ Hydrogenation}

Similarly to the electrochemical reduction, there are only few reports in the literature on $\mathrm{CO}_{2}$ hydrogenation to formaldehyde using heterogeneous catalysts (Heim et al., 2017). Lee et al. (2001) studied the production of formaldehyde via $\mathrm{CO}_{2}$ hydrogenation over a $\mathrm{PtCu} / \mathrm{SiO}_{2}$ catalyst at $423 \mathrm{~K}$ and $600 \mathrm{kPa}$ and varying the $\mathrm{H}_{2} / \mathrm{CO}_{2}$ feed ratio between 3 and 20. The authors reported that the rate of formaldehyde production increased considerably with increase of the $\mathrm{H}_{2} / \mathrm{CO}$ ratio, ranging from $0.21 \times 10^{-4}$ $\mathrm{mol} \mathrm{min^{-1 }} \mathrm{g}_{\text {cat }}^{-1}$ at $\mathrm{H}_{2} / \mathrm{CO}=3-0.87 \times 10^{-4} \mathrm{~mol} \mathrm{~min}^{-1} \mathrm{~g}_{\text {cat }}^{-1}$ at $\mathrm{H}_{2} / \mathrm{CO}=20$. Conversely, the rate of methanol production greatly decreased with an increase of the $\mathrm{H}_{2} / \mathrm{CO}$ ratio. These results led the authors to conclude that the relative concentration of surface hydrogen on the catalyst play a major role in the selective production of formaldehyde. For comparative purposes, $\mathrm{Cu} / \mathrm{SiO}_{2}$ catalyst was also tested in the same conditions. However, in this case, when a $\mathrm{H}_{2} / \mathrm{CO}=20$ was used, the formaldehyde production was negligible. The authors concluded that $\mathrm{Pt}$ played an important role in the adsorption of hydrogen, which would then migrate to the copper surface, promoting the $\mathrm{CO}_{2}$ hydrogenation into formaldehyde.

Chan et al. (2018) recently reported the production of formaldehyde from $\mathrm{CO}_{2}$ hydrogenation in aqueous solution, using formic acid as intermediate of the $\mathrm{CO}_{2}$ hydrogenation process. The performance of the $\mathrm{Pt}-\mathrm{Cu} / \gamma-\mathrm{Al}_{2} \mathrm{O}_{3}, \mathrm{Pt}-\mathrm{Ni} / \gamma-\mathrm{Al}_{2} \mathrm{O}_{3}$, $\mathrm{Ru}-\mathrm{Cu} / \gamma-\mathrm{Al}_{2} \mathrm{O}_{3}$, and $\mathrm{Ru}-\mathrm{Ni} / \gamma-\mathrm{Al}_{2} \mathrm{O}_{3}$ catalysts was evaluated at $70 \mathrm{bar}$ and at a temperature range of $298-363 \mathrm{~K}$. The authors reported that the conversion of formic acid into formaldehyde is possible, despite not been thermodynamically favored, with $\mathrm{Pt}-\mathrm{Cu} / \gamma-\mathrm{Al}_{2} \mathrm{O}_{3}$ being the catalyst with the highest formic acid conversion and formaldehyde yield $\left(\approx 6 \mathrm{mmol} \mathrm{L}^{-1} \mathrm{~g}_{\text {cat }}^{-1}\right)$. However, all the formic acid converted was not transformed into formaldehyde. The authors suggested that this could be related to the thermal decomposition of formic acid. However, they did not evaluate the formation of other products to confirm this hypothesis.

\section{Methanol}

Methanol $\left(\mathrm{CH}_{3} \mathrm{OH}\right)$ is one of the main commodities produced worldwide, with a price around 470 USD per metric ton (2018, Methanex $)^{12}$. It is also an important feedstock in the chemical industry for the production of olefins, dimethyl ether and liquid fuels, thus becoming an interesting alternative to fossil fuels (Goeppert et al., 2014; Dang et al., 2018). Moreover, $\mathrm{CH}_{3} \mathrm{OH}$ is a liquid energy carrier, being easier to handle and transport than gases and solid materials (Onishi et al., 2018).

Methanol is currently produced at commercial scale from fossil fuel-based syngas in a two-step process. In the first step, syngas with a $\mathrm{H}_{2}$ :CO ratio close to $3: 1$ is produced from steam reforming of natural gas (Equation 1). Then, after adjusting the $\mathrm{H}_{2}$ :CO ratio to around 2:1, the syngas is converted into methanol using copper-based catalysts (Equation 9) (Olah et al., 2009; Albo et al., 2015).

$$
\mathrm{CO}+2 \mathrm{H}_{2} \rightleftarrows \mathrm{CH}_{3} \mathrm{OH} \quad \Delta \mathrm{H}_{298 \mathrm{~K}}=-90.7 \mathrm{~kJ} / \mathrm{mol}
$$

\footnotetext{
${ }^{12}$ https://www.methanex.com/our-business/pricing
}

One of the simplest ways to sustainably obtain liquid products from $\mathrm{CO}_{2}$ is the production of methanol mainly electrochemically and through hydrogenation (Goeppert et al., 2014), two pathways that will be detailed in the following sections.

\section{$\mathrm{CO}_{2}$ Electrochemical Reduction}

As for most of the $\mathrm{CO}_{2}$ electrochemical reactions reported in this work, the development of catalysts able to selectively produce methanol still represents a challenge to be overcome. Copper and copper-based electrodes have proved to be one of the most performing materials for the electrochemical conversion of $\mathrm{CO}_{2}$ into alcohols, including methanol (Albo et al., 2015). Frese (1991) was one of the first to investigate the $\mathrm{CO}_{2}$ reduction to methanol over copper surfaces. The authors showed that an anodized $\mathrm{Cu}$ foil could successfully reduce $\mathrm{CO}_{2}$ into methanol using a $0.5 \mathrm{M}$ $\mathrm{KHCO}_{3}$ as solution and $-1.9 \mathrm{~V}$ (vs. SCE) at a rate as high as $10^{-4} \mathrm{~mol} \mathrm{~cm}^{-2} \mathrm{~h}^{-1}$. Faradaic efficiency for $\mathrm{CH}_{3} \mathrm{OH}$ reached about $240 \%$. Efficiencies higher than $100 \%$ were obtained since the theoretical analysis considered six-electron reduction of $\mathrm{CO}_{2}$ to $\mathrm{CH}_{3} \mathrm{OH}$ and $\mathrm{H}_{2} \mathrm{O}$ and the HER also occurred. Similarly, Le et al. (2011) obtained a methanol production rate of $43 \mu \mathrm{mol}$ $\mathrm{cm}^{-2} \mathrm{~h}^{-1}$ and Faradaic efficiency of $38 \%$ in $0.5 \mathrm{M} \mathrm{KHCO}_{3}$ using cuprous oxide thin films at $-1.1 \mathrm{~V}$ (vs. SCE). The authors showed that this rate of methanol production as well as the Faradaic efficiency were much higher than those obtained with air-oxidized $\left(0.9 \mu \mathrm{mol} \mathrm{cm}{ }^{-2} \mathrm{~h}^{-1}\right)$ and anodized $\left(1.5 \mu \mathrm{mol} \mathrm{cm} \mathrm{cm}^{-2}\right.$ $\mathrm{h}^{-1}$ ) copper electrodes, suggesting that $\mathrm{Cu}$ (I) species might play a key role in the electrode activity and selectivity to methanol. Malik et al. (2016) studied the efficiency of multi wall carbon nanotubes (MWCNTs) impregnated with $\mathrm{CuO}_{2}$ to reduce $\mathrm{CO}_{2}$ into methanol, due to their excellent structural and electrical properties, making them good candidates for electrochemical applications. The authors reported that the MWCNTs acted as active sites for $\mathrm{CO}_{2}$ conversion as well as traps for electrons, increasing the rate of conversion of intermediates into methanol. Also, $\mathrm{CuO}_{2}$ loadings varying between 10 and 50 wt.\% were investigated. $30 \% \mathrm{CuO}_{2}$-MWCNTs catalyst showed the best catalytic performance, achieving $38 \%$ of Faradaic efficiency to methanol at $-0.8 \mathrm{~V}$ (vs. $\mathrm{Ag} / \mathrm{AgCl}$ ) in a $0.5 \mathrm{M} \mathrm{NaHCO}_{3}$ medium. $\mathrm{CuO}_{2}$ loadings (higher than $40 \mathrm{wt} . \%$ ) led to an agglomeration of the $\mathrm{CuO}_{2}$ particles and overall larger crystallite sizes, decreasing the surface area of the catalyst and the number of active sites.

The use of copper alloys have also been investigated, since it may enhance the electrochemical $\mathrm{CO}_{2}$ reduction to $\mathrm{CH}_{3} \mathrm{OH}$. Actually, most of the industrial catalysts currently used for methanol production are composed of $\mathrm{Cu}-\mathrm{Zn}$ mixed oxides, highlighting the synergetic effect of the metals to improve methanol production (Frese, 1991; Albo et al., 2015). Watanabe et al. (1991) evaluated the capacity of $\mathrm{Cu}-\mathrm{Ni}, \mathrm{Cu}-\mathrm{Sn}, \mathrm{Cu}-\mathrm{Pb}, \mathrm{Cu}-$ $\mathrm{Zn}, \mathrm{Cu}-\mathrm{Cd}$, and $\mathrm{Cu}-\mathrm{Ag}$ alloys to electrocatalytic reduce $\mathrm{CO}_{2}$ into methanol in a $0.05 \mathrm{M} \mathrm{KHCO}_{3}$ aqueous solution. They observed that the product distribution was dependant on the copper alloy. While a $\mathrm{Cu}-\mathrm{Ni}$ alloy produced $\mathrm{CH}_{3} \mathrm{OH}$ and $\mathrm{HCOOH}, \mathrm{Cu}-\mathrm{Sn}$, and $\mathrm{Cu}-\mathrm{Pb}$ enhanced the production of $\mathrm{HCOOH}$ and $\mathrm{CO} . \mathrm{A}$ Faradaic efficiency to methanol of $10 \%$ was obtained with the $\mathrm{Cu}-$ $\mathrm{Ni}$ alloy at $-0.4 \mathrm{~V}$ (vs. $\mathrm{Ag} / \mathrm{AgCl}$ ) while no $\mathrm{CH}_{3} \mathrm{OH}$ was formed 
when pure $\mathrm{Cu}$ or $\mathrm{Ni}$ were used alone even when a wide potential range from -0.5 to $-1.5 \mathrm{~V}$ was considered. They concluded that this difference in the catalytic performance was related to a mechanism involving the introduction of hydrogen atoms on the alloy surface by Ni sites. Jia et al. (2014) also investigated the performance of copper-based alloys. The authors prepared $\mathrm{Cu}$ $\mathrm{Au}$ alloys through electrochemical deposition with a nanoporous $\mathrm{Cu}$ film (NCF) as template. The $\mathrm{Cu}_{63.9} \mathrm{Au}_{36.1} / \mathrm{NCF}$ alloy showed a Faradaic efficiency of methanol of $15.9 \%$, which was around 19 times higher than that obtained with pure $\mathrm{Cu}$. In fact, the $\mathrm{Cu}-\mathrm{Au}$ alloy favored not only the $\mathrm{CO}_{2}$ reduction reaction but also the $\mathrm{CO}$ reduction, improving the overall conversion of $\mathrm{CO}_{2}$ into methanol.

Kuhl et al. (2014) further investigated the $\mathrm{CO}_{2}$ electrocatalytic reduction over different metals, such as $\mathrm{Au}, \mathrm{Ag}, \mathrm{Zn}, \mathrm{Cu}, \mathrm{Ni}$, $\mathrm{Pt}$, and Fe. Experiments were carried out in $0.1 \mathrm{M} \mathrm{KHCO}_{3}$ electrolyte and at different voltages varying between -1.6 and $-0.4 \mathrm{~V}$ (vs. RHE). The best results were obtained with $\mathrm{Au}$, presenting almost $100 \%$ of Faradaic efficiency to methanol. On the contrary, Fe showed to be inefficient for methanol production under these conditions, presenting $100 \%$ of current efficiency to methane production, instead of methanol. The other metals were able to produce both methanol and methane. The authors reported that one of the main parameters that influences the selectivity to methanol or methane is the oxophilicity (capacity to adsorb oxygen) of the catalyst surface. Au, metal with the lowest oxophilicity among the metals investigated, produced only methanol whereas $\mathrm{Fe}$, metal with the highest oxophilicity, produced only methane.

Since the hydrogen evolution reaction (HER) competes with the $\mathrm{CO}_{2}$ reduction (hence lowering the Faradaic efficiency of the $\mathrm{CO}_{2}$ reduction reaction), Olah and Prakash (2010) investigated the possibility of using the HER as an advantage. The authors used a $0.1 \mathrm{M} \mathrm{KHCO}_{3}$ aqueous solution as electrolyte and water was electrolyzed while $\mathrm{CO}_{2}$ was reduced at an $\mathrm{Au}$ cathode at $-3.2 \mathrm{~V}$ (vs. $\mathrm{Ag} / \mathrm{AgCl}$ ), producing syngas with a $\mathrm{H}_{2}: \mathrm{CO}$ ratio close to 2:1. They showed that the total Faradaic efficiency for $\mathrm{H}_{2}$ and $\mathrm{CO}$ was close to $100 \%$. The syngas produced could then be converted into methanol using the same process that is currently used at industrial scale (Equation 9). The advantages of this process are the high Faradaic efficiencies for syngas production, absence of a purification step since no impurity is present and production of valuable high-purity oxygen at the anode (Olah et al., 2009).

$\mathrm{Ru}$ and $\mathrm{RuO}_{2}$ have also shown to be promising materials to for the electrocatalytic reduction of $\mathrm{CO}_{2}$ due to their high electrical conductivity, high electrochemical stability, intermediate hydrogen overpotential and capacity to reversibly adsorb hydrogen for $\mathrm{CO}_{2}$ reduction (Qu et al., 2005). Bandi (1990) reported that electrodes composed of 35\% Ru and 65\% $\mathrm{TiO}_{2}$ presented current efficiencies for methanol production as high as $24 \%$ when polarized near the equilibrium potential of hydrogen evolution in solutions of $0.2 \mathrm{M} \mathrm{Na}_{2} \mathrm{SO}_{4}$ saturated with $\mathrm{CO}_{2}$. The results led the authors to conclude that the first electron transfer is the rate-determining step in electrochemical reduction of $\mathrm{CO}_{2}$ on oxide surfaces at low $\mathrm{pH}$. Finally, the authors suggested that the methanol efficiency could be improved by changing the oxide composition and preparation parameters. $\mathrm{Qu}$ et al. (2005) investigated the electrochemical $\mathrm{CO}_{2}$ reduction properties of $\mathrm{RuO}_{2} / \mathrm{TiO}_{2}$ nanoparticles (NPs) and nanotubes (NTs). $\mathrm{RuO}_{2} / \mathrm{TiO}_{2}$ NTs showed a Faradaic efficiency for $\mathrm{CH}_{3} \mathrm{OH}$ of $60.5 \%$ at $-0.8 \mathrm{~V}$ (vs. SCE) in $0.5 \mathrm{M} \mathrm{NaHCO}_{3}$, which was about $20 \%$ higher than that obtained with $\mathrm{RuO}_{2} / \mathrm{TiO}_{2} \mathrm{NPs}$. The authors reached similar conclusions to Malik et al. (2016), suggesting that the surface structure of the nanotubes composite had an important role for achieving high efficiency and selectivity to the desired products. Table 3 summarizes the performance of different catalysts for $\mathrm{CO}_{2}$ electrochemical reduction into $\mathrm{CH}_{3} \mathrm{OH}$ reported in the literature.

\section{$\mathrm{CO}_{2}$ Hydrogenation}

The most direct way to produce methanol from $\mathrm{CO}_{2}$ via a $\mathrm{PtX}$ process is the catalytic hydrogenation showed in Equation (10):

$$
\mathrm{CO}_{2}+3 \mathrm{H}_{2} \rightleftharpoons \mathrm{CH}_{3} \mathrm{OH}+\mathrm{H}_{2} \mathrm{O} \quad \Delta \mathrm{H}_{298 \mathrm{~K}}=-49.2 \mathrm{~kJ} / \mathrm{mol}
$$

The reaction takes place at $250-300^{\circ} \mathrm{C}$ and $50-100$ bars usually in the presence of $\mathrm{CuO} / \mathrm{ZnO} / \mathrm{Al}_{2} \mathrm{O}_{3}$ catalysts (Jadhav et al., 2014; Bellotti et al., 2017). In this process, hydrogen is produced by water electrolysis ideally using renewable energy, as presented in section Water Electrolysis, and then combined with $\mathrm{CO}_{2}$ waste streams to produce methanol, in a classical Power-toMethanol process.

Recent process simulations and techno-economic studies have focused on the efficiency of Power-to-Methanol processes and on its comparison with the classical routes (Table 4). RihkoStruckmann et al. (2010) investigated the idea of capturing the $\mathrm{CO}_{2}$ from power plants to produce energy storage media, such as $\mathrm{H}_{2}$ and methanol. They considered a $\mathrm{H}_{2}$ production from water electrolysis and the methanol production from a Power-toMethanol technology at $220^{\circ} \mathrm{C}$ and $5 \mathrm{MPa}$. They achieved a high $\mathrm{CO}_{2}$ conversion of about $97 \%$. However, they concluded that the exergetic efficiency of the system using hydrogen as storage medium was higher than the one including methanol. The main advantage of using methanol as chemical storage system would be, however, its simple and cost-efficient storage. Hank et al. (2018) evaluated the economic feasibility of a methanol plant with a methanol production capacity of $4-10 \mathrm{kt} / \mathrm{y}$ using $\mathrm{CO}_{2}$ and hydrogen as feedstock. The hydrogen used in the process was produced via a PEM water electrolyser with an electricity consumption of $4.76 \mathrm{kWh} / \mathrm{m}^{3} \mathrm{H}_{2}$. They concluded that the feasibility of the process strongly depended on the costs of electricity and of $\mathrm{H}_{2}$ production, on the price of the $\mathrm{CO}_{2}$ (considering the carbon taxes) as well as on the dynamics of the methanol reactor including the necessity of $\mathrm{H}_{2}$ storage. They also concluded that locations with high availability and low cost production of renewable energy will play an important role on the development of Power-to-Methanol technologies in the next few years. Bellotti et al. (2017) compared the economic feasibility of three different plant sizes for methanol synthesis from hydrogen, produced by water electrolysis, and carbon dioxide, sequestrated from power plants. They concluded that in the case of large plant sizes with a methanol production around $50 \mathrm{kt} / \mathrm{y}$ considerable amounts of $\mathrm{CO}_{2}(71.6 \mathrm{kt} / \mathrm{y})$ would be sequestrated. However, 
TABLE 3 | Summary of different electrocatalysts used for electrocatalytic reduction of $\mathrm{CO}_{2}$ in methanol.

\begin{tabular}{|c|c|c|c|c|c|}
\hline Catalyst & Medium (electrolyte) & $E(V)$ & $\mathrm{CH}_{3} \mathrm{OH}$ production rate & Faradaic efficiency (\%) & References \\
\hline Cu foil & $0.5 \mathrm{M} \mathrm{KHCO}_{3}$ & $-1.9 \mathrm{~V}$ vs. SCE & $10^{-4} \mathrm{~mol} \mathrm{~cm}^{-2} \mathrm{~h}^{-1}$ & 240 & Frese, 1991 \\
\hline Cuprous oxide thin films & $0.5 \mathrm{M} \mathrm{NaHCO}_{3}$ & -1.1 vs. SCE & $0.43 \times 10^{-4} \mathrm{~mol} \mathrm{~cm}^{-2} \mathrm{~h}^{-1}$ & 38 & Le et al., 2011 \\
\hline $\mathrm{CuO}_{2}-\mathrm{MWCNTS}$ & $0.5 \mathrm{M} \mathrm{NaHCO}_{3}$ & -0.8 vs. $\mathrm{Ag} / \mathrm{AgCl}$ & - & 38 & Malik et al., 2016 \\
\hline $\mathrm{Cu}-\mathrm{Ni}$ & $0.05 \mathrm{M} \mathrm{KHCO}_{3}$ & $-0.4 \mathrm{~V}$ vs. $\mathrm{Ag} / \mathrm{AgCl}$ & - & 10 & Watanabe et al., 1991 \\
\hline $\mathrm{Cu}_{63.9} \mathrm{Au}_{36.1} / \mathrm{NCF}$ & $0.5 \mathrm{M} \mathrm{KHCO}_{3}$ & -1.1 vs. SCE & - & 15.9 & Jia et al., 2014 \\
\hline $\mathrm{Au}$ & $0.1 \mathrm{M} \mathrm{KHCO}_{3}$ & -0.7 vs. REH & - & $\approx 100$ & Kuhl et al., 2014 \\
\hline $\mathrm{Pt} \mathrm{RuO}_{2} / \mathrm{TiO}_{2} \mathrm{NTs}$ (nanotubes) & $0.5 \mathrm{M} \mathrm{NaHCO}_{3}$ & -0.8 vs. SCE & - & 60.5 & Qu et al., 2005 \\
\hline $\mathrm{RuO}_{2}+\mathrm{TiO}_{2}$ & $0.05 \mathrm{M} \mathrm{H}_{2} \mathrm{SO}_{4}$ & -0.9 vs. $\mathrm{Hg}_{2} \mathrm{SO}_{4}$ & - & 24 & Bandi, 1990 \\
\hline
\end{tabular}

due to the high cost of the plant, oxygen selling would be mandatory to get economically feasible results. Koytsoumpa et al. (2018) showed that a large-scale methanol plant with a methanol production of 50-100 kt/y would require 1.01 MWhth per ton of $\mathrm{CH}_{3} \mathrm{OH}$ of thermal energy and 9.74 MWhe/ $\mathrm{CH}_{3} \mathrm{OH}$ of electric energy. The techno-economics are highly influenced by the final methanol price, the fuel and chemical market as well as the energy and fuel directives. Kourkoumpas et al. (2016) performed a techno-economic evaluation of the Power-to-Methanol concept using $\mathrm{CO}_{2}$ from lignite-fired power plants and $\mathrm{H}_{2}$ from water electrolysis. They concluded that the Power-to-Methanol concept is more competitive when large scale plants, low electricity, low $\mathrm{CO}_{2}$ costs and high operating time for both $\mathrm{H}_{2}$ and methanol plants are considered.

A few Power-to-Methanol plants are actually already in operation and projects aiming at building pilot and demonstration plants are currently being developed. The European Commission has launched the $\mathrm{MefCO}_{2}$ project aiming to demonstrate the economic feasibility of the Powerto-Methanol technology in a modular intermediate scale and to adapt it to varying plant sizes and gas composition. The technology could later be adapted to work with the existing biomass combustion and gasification system streams, for example, aiming in this case the production of electric/thermal energy instead of chemical synthesis ${ }^{1314}$ (Koytsoumpa et al., 2018). Mitsui Chemicals built a pilot plant in 2008 for methanol production from $\mathrm{CO}_{2}$ and $\mathrm{H}_{2}$ obtained from water photolysis with a capacity of 100 tons of $\mathrm{CH}_{3} \mathrm{OH}$ per year. Their objective is to use the methanol produced as raw material to the synthesis of olefins and aromatics ${ }^{15}$ (Pérez-Fortes et al., 2016). Carbon Recycling International (CRI) has taken the technology one step further since the company developed an emission-to-liquid technology in which $\mathrm{CO}_{2}$ captured from flue gas of a geothermal power plant and $\mathrm{H}_{2}$ produced from water electrolysis using renewable energy are used to produce renewable methanol. The George Olah plant recycles 5.5 thousand tons of $\mathrm{CO}_{2}$ per year, releasing $90 \%$ less $\mathrm{CO}_{2}$ than the use of a comparable amount of energy from fossil fuels ${ }^{16}$.

\footnotetext{
$\overline{13}$ http://www.mefco2.eu/mefco2.php,

${ }^{14}$ https://cordis.europa.eu/project/rcn/193453_en.html

${ }^{15}$ https://www.mitsuichem.com/en/release/2008/080825e.htm

${ }^{16} \mathrm{http}: / /$ carbonrecycling.is/george-olah/
}

\section{Methane}

Methane $\left(\mathrm{CH}_{4}\right)$ is one of the most important energy vectors of our society, being used to produce heat, electricity and valueadded chemicals. Methane is mainly obtained through natural gas, a fossil fuel source with very low cost $(\approx 3.13 \mathrm{USD} / \mathrm{GJ}-$ December 2018) ${ }^{17}$. If produced in a sustainable way, $\mathrm{CH}_{4}$, also called substitute natural gas (SNG), has also a great potential for reducing the GHG emissions, since it can be more readily used than renewable $\mathrm{H}_{2}$, for example. Indeed, SNG can be injected directly into the natural gas grid, benefiting of the existing natural gas facilities (Götz et al., 2016). Power-to-Methane (PtM) technology has shown to be a promising pathway for a sustainable production of methane, using $\mathrm{CO}_{2}$ and renewable energy to produce SNG. Among the different existing routes for PtM, catalytic $\mathrm{CO}_{2}$ hydrogenation (methanation) has been extensively investigated and demonstration plants are already in operation in different countries. $\mathrm{CO}_{2}$ electrochemical reduction route is still at lab-scale validation stage. However, the results obtained over the last few years have highlighted the promising aspects of this route.

\section{$\mathrm{CO}_{2}$ Electrochemical Reduction}

One of the possible ways to sustainably produce fuels (such as methane from $\mathrm{CO}_{2}$ ) is by an electrochemical reduction of $\mathrm{CO}_{2}$. Thermodynamically, $\mathrm{CO}_{2}$ can be electrochemically reduced to $\mathrm{CH}_{4}$ with a standard potential of $+0.17 \mathrm{~V}$ vs. RHE (Peterson and Norskov, 2012). However, since hydrogen evolution reaction (HER) is thermodynamically possible at $0 \mathrm{~V}$ (vs. RHE), both reactions will be in competition at all negative potentials (Peterson and Norskov, 2012). The low $\mathrm{CO}_{2}$ solubility in water $\left(0.03 \mathrm{M}, 25^{\circ} \mathrm{C}\right.$ and $\left.1 \mathrm{~atm}\right)$ is also a remaining challenge. So, studies are still needed to improve $\mathrm{CO}_{2}$ solubility and to develop catalysts able to improve selectivity to methane and to reduce the high potentials required. Alternative approaches to $\mathrm{CO}_{2}$ electrochemical reduction, such as photo irradiation, use of ionic liquid electrolytes and use of biological microorganisms have also been treated elsewhere (Kondratenko et al., 2013; Machado et al., 2018) and are not the focus of this section.

Hori et al. (1994) pioneered experimental works on the comprehension of $\mathrm{CO}_{2}$ electrochemical reduction by heterogeneous catalysts. The authors performed $\mathrm{CO}_{2}$ reduction tests at $18.5^{\circ} \mathrm{C}$ in a $0.1 \mathrm{M} \mathrm{KHCO}_{3}$ medium using different metals,

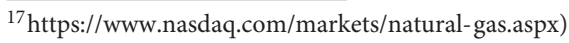


TABLE 4 | Summary of some of the process simulations and techno-economic studies about Power-to-Methanol reported in the literature.

\begin{tabular}{lccccccc}
\hline $\mathbf{T}\left({ }^{\circ} \mathbf{C}\right)$ & $\mathbf{P}$ (bar) & $\begin{array}{c}\mathbf{C O}_{\mathbf{2}} \text { conversion } \\
\text { to } \mathbf{M e O H}(\mathbf{\%})\end{array}$ & $\begin{array}{c}\text { Methanol } \\
\text { production }\end{array}$ & $\begin{array}{c}\text { Electricity consumption } \\
\mathbf{( k W h / k g ~ M e O H )}\end{array}$ & $\mathbf{H}_{\mathbf{2}}$ source & $\begin{array}{c}\text { Electricity consumption References } \\
\left.\mathbf{( k W h} / \mathbf{m}^{\mathbf{3}} \mathbf{H}_{\mathbf{2}}\right)\end{array}$ \\
\hline- & 40 & 90 & $4-10 \mathrm{kton} / \mathrm{y}$ & - & Water electrolysis (PEM) & 4.76 & Hank et al., 2018 \\
240 & 80 & 96 & $97 \mathrm{~kg} / \mathrm{h}$ & - & Water electrolysis (PEM) & 5.2 & Bellotti et al., 2017 \\
220 & 50 & 96.8 & $3.03 \mathrm{kmol} / \mathrm{h}$ & - & Water electrolysis & - & Rihko-Struckmann et al., 2010 \\
- & - & - & $50-100 \mathrm{kton} / \mathrm{y}$ & 9.89 & Water electrolysis (AEL) & 4.4 & Koytsoumpa et al., 2018 \\
\hline
\end{tabular}

such as $\mathrm{Cu}, \mathrm{Au}, \mathrm{Ag}, \mathrm{Zn} \mathrm{Pd}, \mathrm{Cd}, \mathrm{Ni}, \mathrm{Pt}$, etc. They proved that methane could be obtained by $\mathrm{CO}_{2}$ electrocatalytic reduction on metal surfaces and that the choice of the metal of the electrode had an impact of the products selectivity. The only metal investigated that presented a relatively high Faradaic efficiency to $\mathrm{CH}_{4}(33.3 \%)$ was copper at $-1.44 \mathrm{~V}$ vs. normal hydrogen electrode (NHE). $\mathrm{Pd}, \mathrm{Cd}$, and $\mathrm{Ni}$ also produced $\mathrm{CH}_{4}$ but with Faradaic efficiencies lower than 3\%, mainly due to the HER occurring as side reaction. The good performance of copper was attributed to the fact that $\mathrm{CO}_{2}$ is intermediately reduced to $\mathrm{CO}$, before being reduced to methane (and other hydrocarbons and alcohols). When other metals, such as $\mathrm{Ni}$ and Pt were used, the $\mathrm{CO}$ was adsorbed on the surface of the electrodes, preventing its further reduction into hydrocarbons and alcohols.

To the best of our knowledge, the best $\mathrm{CH}_{4}$ Faradaic efficiency obtained up to date on copper electrodes was obtained by Manthiram et al. (2014). The authors compared the performance of copper nanoparticles supported on glassy carbon $(n-C u / C)$ with classical copper foils. The electrochemical tests were performed in a two-compartment electrochemical flow cell separated by a Selemion membrane and in a $0.1 \mathrm{M} \mathrm{NaHCO}_{3}$ electrolyte. A Faradaic efficiency for $\mathrm{CH}_{4}$ of $76 \%$ was obtained using $\mathrm{n}-\mathrm{Cu} / \mathrm{C}(-1.35 \mathrm{~V}$ vs. $\mathrm{RHE})$, which was significantly higher than the Faradaic efficiency of $44 \%$ obtained with the classical copper foil. The good performance of the $\mathrm{n}-\mathrm{Cu} / \mathrm{C}$ catalyst was attributed to the formation of nanoscale aggregates on the $\mathrm{n}-\mathrm{Cu} / \mathrm{C}$ upon polarization, exposing its catalytic sites to methanation. On the other hand, in copper foils highly connected networks of fused particles are formed upon polarization, leading to less exposed catalytic sites.

The electrolyte concentration as well as the local $\mathrm{pH}$ have also shown to have great influence on the selectivity of the $\mathrm{CO}_{2}$ electrochemical reduction. It has been proved that the methane formation depends on proton concentrations, being favored when acidic or neutral solutions are used. Thus, the effect of the electrolyte can be directly linked to the local $\mathrm{pH}$. Varela et al. (2016) investigated the effect of the concentration of the electrolyte in controlling the selectivity of the $\mathrm{CO}_{2}$ electroreduction on copper. $\mathrm{KHCO}_{3}$ electrolyte solutions were used with concentrations varying between 0.05 and $0.2 \mathrm{M}$ $\mathrm{KHCO}_{3}$. The highest concentrations of electrolyte favored the selectivity to methane. $\mathrm{CH}_{4}$ Faradaic efficiency of $\approx 70 \%$ at $-1.43 \mathrm{~V}$ (vs. NHE) was obtained when a $0.2 \mathrm{M} \mathrm{KHCO}_{3}$ solution was used, due to its higher buffer capacity. The authors hypothesized that concentrated $\mathrm{KHCO}_{3}$ solutions had a higher buffer capacity and favored the electron/proton couple transfer, resulting in a higher methane (and $\mathrm{H}_{2}$ ) production. On the other hand, methane formation was less favored in diluted $\mathrm{KHCO}_{3}$ solution with low buffer capacity, due to the low concentration of protons close to electrode surface.

Issues related to the low $\mathrm{CO}_{2}$ solubility in water often leads to mass transfer limitations for large current densities. To overcome such problem, Hara et al. (1995) performed $\mathrm{CO}_{2}$ reduction using gas diffusion electrodes (GDE). Electrolysis experiments were carried out at $30 \mathrm{~atm}$ in a stainless steel autoclave using a $0.5 \mathrm{M} \mathrm{KHCO} 3$ aqueous electrolyte and a gas diffusion electrode containing $\mathrm{Pt}$ electrocatalysts. The $\mathrm{Pt}$ catalyst layer was directed toward the $\mathrm{CO}_{2}$ gas phase while the gas diffusion layer faced the aqueous electrolyte. Methane was produced with a Faradaic efficiency of $34.8 \%$ at a $-1.92 \mathrm{~V}$ (vs. $\mathrm{Ag} / \mathrm{AgCl}$ ). However, when the order of the layers was inversed (Pt catalyst layer facing aqueous electrolyte), negligible amounts of methane were produced, mainly due to the contact between the water and the Pt catalyst, favoring the hydrogen evolution reaction.

Also aiming to improve $\mathrm{CO}_{2}$ solubility, Kaneco et al. (2002) investigated the electrochemical reduction of $\mathrm{CO}_{2}$ to methane at low temperatures in methanol, since it is a better solvent for $\mathrm{CO}_{2}$ as compared to water. Experiments were performed in a H-type cell with a Nafion 117-type ion exchange membrane as diaphragm using $\mathrm{Cu}$ electrodes. The authors reported a $\mathrm{CH}_{4}$ Faradaic efficiency of $58 \%$ at $-2.0 \mathrm{~V}$ (vs. Ag QRE). The authors further investigated the use of different sodium salts $\left(\mathrm{NaNO}_{3}\right.$, $\mathrm{NaH}_{2} \mathrm{PO}_{4}, \mathrm{NaHCO}_{3}, \mathrm{NaCl}, \mathrm{NaBr}, \mathrm{NaI}, \mathrm{NaF}, \mathrm{Na}_{2} \mathrm{SO}_{4}, \mathrm{NaSCN}$, $\mathrm{NaClO}_{4}$, and $\mathrm{CH}_{3} \mathrm{COONa}$ ) to further increase the $\mathrm{CO}_{2}$ solubility in methanol (Kaneco et al., 2006). The electrolysis tests were performed at $243 \mathrm{~K}$ using $\mathrm{Cu}$ electrodes. The authors reported that for all the sodium salts tested, $\mathrm{CH}_{4}$ Faradaic efficiencies $\geq$ $43.4 \%$ were obtained, $70.5 \%$ being the highest efficiency obtained using $\mathrm{NaClO}_{4}$. These results were attributed to the fact that the sodium salts depressed the hydrogen evolution reaction that competes with the $\mathrm{CO}_{2}$ reduction, thus increasing the methane formation.

\section{$\mathrm{CO}_{2}$ Hydrogenation}

Power-to-Methane (PtM) can also be achieved by combining water electrolysis for $\mathrm{H}_{2}$ production with methanation process in a two-step process. In the first step, $\mathrm{H}_{2}$ is produced using renewable energy, such as solar and wind power. In the second step, $\mathrm{CO}_{2}$ is hydrogenated in a methanation process to produce methane (Equation 11). Since the substitute natural gas (SNG) produced has high purity, it can be injected directly into the natural gas grid, stored or used in natural gas facilities (Götz et al., 2016), allowing this technology to connect the electrical and gas 
grids in a single system, procuring great flexibility to the balance of the grid (Bailera et al., 2017).

$$
\mathrm{CO}_{2}+4 \mathrm{H}_{2} \rightleftharpoons \mathrm{CH}_{4}+2 \mathrm{H}_{2} \mathrm{O} \quad \Delta \mathrm{H}_{298 \mathrm{~K}}=-164.9 \mathrm{~kJ} / \mathrm{mol}
$$

Methanation can be done either biologically or catalytically. However, the focus of this section will be on catalytic methanation, since it is (to the best of our knowledge) the most advanced technology. Catalytic methanation (Equation 11) is an exothermic reaction usually performed between 200 and $550^{\circ} \mathrm{C}$ and at pressures up to 100 bar. Due to its exothermicity, temperature control inside the reaction is an issue that can lead to thermodynamic limitations and catalyst deactivation by sintering (Götz et al., 2016). Therefore, different reactors types, such as fixed bed, fluidized bed, three-phase and structured reactors have been used to improve the efficiency of the process. Adiabatic fixed-bed reactor is the most commonly studied reactor type and is actually employed by companies such as Sasol, Linde, Haldor Topsoe etc., for the production of SNG from coal or naphtha (Schaaf et al., 2014; Götz et al., 2016). However, catalysts must be resistant against sintering due to the large temperature range they have to support because of the adiabatic mode (Götz et al., 2016). Usually, there are at least two fixed bed reactors connected in series for a good control of the reaction temperature, which is done by recirculating the reactor outlet gas stream and by intermediate gas cooling steps (Schaaf et al., 2014). Fluidized bed reactor is the second reactor type most commonly studied where the methanation reactions occur in a fluidized catalyst bed, improving heat and mass transfer during the reaction and thus the control of the process. Nevertheless, abrasion and entrainment of catalyst bed particles are some drawbacks of this type of reactor (Schaaf et al., 2014).

The catalyst has also a significant impact on the efficiency of the methanation process and Nickel-based catalysts are commonly used to this purpose due to their high activity and low cost (Ghaib and Ben-Fares, 2018). However, they impose limits to the methanation process, such as operating temperatures that must be kept between 200 and $550^{\circ} \mathrm{C}$ since potentially highly toxic nickel compounds can be formed at $200^{\circ} \mathrm{C}$ and catalyst deactivation by sintering and coking can occur above $550^{\circ} \mathrm{C}$ (Schaaf et al., 2014). So, studies have been carried out on catalyst development, aiming at synthetizing more performing and temperature-resistant catalysts. Bacariza et al. (2019) investigated the effect of the zeolite structure on the performances of $\mathrm{Ni}$ based catalysts for $\mathrm{CO}_{2}$ methanation. Commercial available USY, BEA, ZSM-5 and MOR zeolites ion-exchanged with $\mathrm{Na}^{+}$and $\mathrm{Cs}^{+}$ and impregnated with $15 \mathrm{wt} . \% \mathrm{Ni}$ were tested at temperatures ranging from 250 to $450^{\circ} \mathrm{C}$ and GHSV of $43,000 \mathrm{~h}^{-1}$. The authors concluded that the performance of the catalysts was intimately related to the structure of the zeolites. USY zeolite showed the best catalytic performance with $\mathrm{CO}_{2}$ conversions of about $70 \%$ and $\mathrm{CH}_{4}$ selectivity close to $100 \%$. The good catalytic performance was attributed to its weak interaction with water, which has an inhibitory role in the reaction, and to the high dispersion of the Ni particles over the catalyst surface. BEA zeolite led to the highest Ni particles dispersion and thus presented similar catalytic performances to the USY zeolite. Also, the catalytic performance of the BEA zeolite was improved when its hydrophobicity was increased by increasing its $\mathrm{Si} / \mathrm{Al}$ ratio. Finally, ZSM-5 and MOR zeolites presented the lowest $\mathrm{Ni}$ dispersion, leading to lower methane selectivity around $60-70 \%$.

Hydrotalcite materials have also been investigated due to the possibility of receiving high amounts of active phase while keeping high metal dispersion (Frontera et al., 2017), favoring $\mathrm{CO}_{2}$ conversion and preventing the catalyst deactivation. Abate et al. (2016) compared the performance of $\mathrm{Ni}-\mathrm{Al} /$ hydrotacilte catalysts with a classical $\mathrm{Ni} / \mathrm{Al}_{2} \mathrm{O}_{3}$ catalyst both doped with 75 wt.\% Ni. The Ni-Al/hydrotacilte presented the best catalytic performance with a $\mathrm{CO}_{2}$ conversion of $85 \%$ and $\mathrm{CH}_{4}$ selectivity of about $85 \%$ at $275^{\circ} \mathrm{C}$, while the $\mathrm{Ni} / \mathrm{Al}_{2} \mathrm{O}_{3}$ commercial catalyst presented a $\mathrm{CO}_{2}$ conversion of around $80 \%$ and $\mathrm{CH}_{4}$ selectivity of about $75 \%$ at the same temperature. The difference in the catalytic performances was attributed to a higher nickel dispersion and a higher metal surface area of the $\mathrm{Ni}-\mathrm{Al} /$ hydrotacilte catalyst. Similar results were obtained by $\mathrm{He}$ et al. (2014). The authors compared the performance of a $\mathrm{Ni}-\mathrm{Al} /$ hydrotacilte catalyst with a $\mathrm{Ni} / \mathrm{Al}_{2} \mathrm{O}_{3}$ catalyst both doped with 78 wt.\% of $\mathrm{Ni}$. Ni-Al/hydrotacilte catalyst presented a better catalytic performance with $\mathrm{CO}_{2}$ conversion of $82.5 \%$ and $\mathrm{CH}_{4}$ selectivity of $99.5 \%$ at $350^{\circ} \mathrm{C}$, which was also attributed to a high nickel dispersion.

Noble metals have also been extensively investigated due to their good catalytic performance for $\mathrm{CO}_{2}$ methanation at low temperatures and good resistance to carbon formation (Frontera et al., 2017; Qin et al., 2017). Karelovic and Ruiz (2012) studied the performance of $\mathrm{Rh} / \gamma-\mathrm{Al}_{2} \mathrm{O}_{3}$ catalyst with $\mathrm{Rh}$ content varying between 1 and 5 wt.\% at a temperature range of $50-200^{\circ} \mathrm{C}$. They reported that selectivity to methane was about $100 \%$ in all conditions investigated. They also reported that the turnover frequency (TOF) of methane formation decreased as the Rh dispersion decreased (increase in Rh content) in a temperature range of $135-165^{\circ} \mathrm{C}$. However, the TOF was independent of the $\mathrm{Rh}$ dispersion in a higher temperature range $\left(185-200^{\circ} \mathrm{C}\right)$. Swalus et al. (2012) investigated the effect of mechanically mixing $\mathrm{Rh} / \gamma-\mathrm{Al}_{2} \mathrm{O}_{3}$ with $\mathrm{Ni} /$ activated carbon (AC) catalyst, a catalyst widely used for hydrogenation reactions. The objective was to verify the synergetic effect of the two catalysts in the $\mathrm{CO}_{2}$ methanation reaction. The reactions were performed at $125^{\circ} \mathrm{C}$ and 2 bar. The authors reported a higher methane production $\left(9.5 \mu \mathrm{molCH}_{4} / \mathrm{g}_{\text {cat }}\right)$ when both catalysts were used compared to when only $\mathrm{Rh} / \gamma-\mathrm{Al}_{2} \mathrm{O}_{3}\left(6.8 \mu \mathrm{molCH}_{4} / \mathrm{g}_{\text {cat }}\right)$ or $\mathrm{Ni} / \mathrm{AC}\left(0 \mu \mathrm{molCH}_{4} / \mathrm{g}_{\mathrm{cat}}\right)$ was used. Since no new structures were formed when the catalysts were mixed, the synergy was attributed to the cooperation between the two catalysts during the reaction. $\mathrm{Rh} / \gamma-\mathrm{Al}_{2} \mathrm{O}_{3}$ was highly efficient for adsorbing $\mathrm{CO}_{2}$ while $\mathrm{Ni} / \mathrm{AC}$ was able to adsorb high quantities of $\mathrm{H}_{2}$. These two properties together improved the $\mathrm{CO}_{2}$ conversion and the $\mathrm{CH}_{4}$ formation. The authors suggested the hydrogen species would migrate from the surface of the $\mathrm{Ni} / \mathrm{AC}$ toward the $\mathrm{Rh} / \gamma$ $\mathrm{Al}_{2} \mathrm{O}_{3}$, reacting with the adsorbed $\mathrm{CO}_{2}$ to produce $\mathrm{CH}_{4}$. Basic promoters, such as $\mathrm{K}, \mathrm{Ba}$ and $\mathrm{CeO}_{2}$ have also been studied to enhance the performance of the catalysts by modifying the surface basicity, the metal-support interaction as well as the metal dispersion. All these parameters would lead to a better activity, stability and resistance to extreme conditions of the catalysts (Ghaib and Ben-Fares, 2018). 
As previously presented, there has been a lot of work on the different steps of the Power-to-Methane process, such as electrolysis and $\mathrm{CO}_{2}$ methanation. However, a lot of work still need to be done on the integration of these steps. Different countries, especially in Europe, driven by the need to increase the share of renewable energy started research projects to provide proof of concept to the Power-to-Methane technology. There are a few plants using this technology that are already in operation and others that are still been developed. A non-exhaustive list of these plants and projects is provided in Table 5.

The largest Power-to-Methane facility in the world is the $6 \mathrm{MW}$ Audi e-gas plant. In this plant, hydrogen is produced by alkaline electrolysers using wind power. The source of the $\mathrm{CO}_{2}$ is the biogas from the EWE Biogas $\mathrm{GmbH} \& \mathrm{Co}$. KG biomethane plant. The methane production is limited to 1,000 $\mathrm{t} / \mathrm{y}$ due to availability of the renewable energy. However, the maximum methane production capacity of the plant is 325 $\mathrm{Nm}^{3} / \mathrm{h}$ (Bailera et al., 2017).

ZSW launched in 2012 a Power-to-Methane demonstration plant composed by a $250-\mathrm{kWel}$ alkaline high-pressure electrolyser, a $\mathrm{CO}_{2}$ methanation unit and a process control system $^{18}$ (Ghaib and Ben-Fares, 2018). In this plant, two different reactor types (tube bundle and plate reactors) can be operated separately or in combination. Also, a membrane gas processing stage is used to enrich the methane in the product gas and to recycle the hydrogen-rich gas (Schildhauer and Biollaz, 2016).

The Store\&Go project funded by the European Union developed a metallic honeycomb-like carrier-based reactor aiming at overcoming the issues related to removing and reutilizing the heat from the methanation reactor (Schollenberger et al., 2018). The proof of concept was done at laboratory scale. The technology was scaled up to a 1MW SNG plant, which started its operations in $2018^{19}$.

The HELMETH project, co-financed by the European Union and by the Fuel Cells and Hydrogen Joint Technology Initiative, aims at determining the conditions for an economic feasibility of the Power-to-Gas process and at demonstrating the technical feasibility with conversion efficiency $>85 \%{ }^{20}$. (Ghaib and Ben-Fares, 2018). The innovation of this project is the thermally integration of a high temperature electrolysis (SOEC) with methanation. The heat released during the methanation process will be used to vaporize the water that will be fed to the electrolyser, helping balancing the endothermal and exothermal process and allowing a better energy-efficiency storage of the renewable energy ${ }^{14}$.

Despite the key role that this technology might play in the future energy sector, further studies are still needed to validate the whole system as well as to overcome main drawbacks, such as low efficiency and high costs (Götz et al., 2016).

\footnotetext{
${ }^{18}$ https://www.zsw-bw.de/en/research/renewable-fuels/topics/power-to-gas.html

${ }^{19} \mathrm{https} / / /$ www.storeandgo.info/press-media/

${ }^{20} \mathrm{http}: / /$ www.helmeth.eu/index.php/technologies/methanation-process
}

\section{Alkanes}

The transportation sector is one the sectors having the largest GHG emissions in many countries. In Canada, for example, the transportation sector accounted for $25 \%$ (173 $\mathrm{Mt} \mathrm{CO}_{2 \mathrm{eq}}$ ) of the total national emissions ${ }^{21}$, showing the critical need to displace the fossil fuels used in the sector to effectively reduce the GHG emissions of the country. Electric cars represent a promising alternative, however, these technologies are not yet optimized for long distance trips and are still unfit for heavy transportation. Biofuels have also been considered as a promising approach, though its use has raised a lot of questions regarding the amounts that can really be produced to significantly reduce the GES emissions from this sector (Schmidt et al., 2018). The challenge is even bigger when it comes to the aviation sector, since there is not yet a reliable substitute to the fossil-based jet fuel. The Powerto-Liquids (PtL) technology could represent a huge opportunity to produce a replacement fuel without the issues related to the biomass feedstock and that could actually reduce the emissions from the transportation sector, especially the aviation sector.

Fischer-Tropsch and methanol are the two main production pathways to produce alkanes through PtL technologies (Figure 4). To fit with the Fischer-Tropsch pathway, $\mathrm{CO}_{2}$ first is converted to $\mathrm{CO}$ via a reverse water-gas shift reaction (RWGS) and $\mathrm{H}_{2}$ is produced through water electrolysis (Schmidt et al., 2016). $\mathrm{H}_{2}$ and $\mathrm{CO}$ are then used in a classical Fischer-Tropsch synthesis to produce hydrocarbons that can be upgraded to fuels such as gasoline, diesel and jet fuel. There are several upgrading processes that are already widely employed for upgrading crude oil to jet fuel that could also be applied in the PtL, such as hydrocracking, isomerization and distillation (Schmidt et al., 2016). In the methanol pathway, $\mathrm{H}_{2}$ produced from water electrolysis, and $\mathrm{CO}_{2}$ (or $\mathrm{CO}$ ) are used in the synthesis of methanol as an intermediate. Methanol can be then converted to fuels through further steps already used at industrial scale, such as DME synthesis, olefin synthesis, oligomerization, and hydrotreating (Schmidt et al., 2016).

To the best of our knowledge, there is no known reports relating the direct electrochemical reduction of $\mathrm{CO}_{2}$ into long chain hydrocarbons. Most of the $\mathrm{CO}_{2}$ hydrogenation studies focus on the synthesis of short-chain products, such as methane, methanol, formic acid etc., as presented in the previous sections. Nevertheless, recent studies reported the successful production of gasoline, diesel and jet fuel either via FT pathway or via $\mathrm{MeOH}$ pathway (Figure 4). The following sections will present a few recent studies on the production of these alkanes via $\mathrm{CO}_{2}$ hydrogenation.

\section{Gasoline}

Gasoline $\left(\mathrm{C}_{5}-\mathrm{C}_{11}\right.$ hydrocarbons) is one of the most important transportation fuel used worldwide. Besides the classical production through petroleum refining, it can be synthesized via Fischer-Tropsch (direct route) or via methanol as intermediate (indirect route). This section will present the recent advances on gasoline production through these two pathways.

\footnotetext{
${ }^{21}$ https://www.canada.ca/en/environment-climate-change/services/ environmental-indicators/greenhouse-gas-emissions.html
} 
TABLE 5 | Summary of the PtM plants current in operation and of the PtM projects being developed.

\begin{tabular}{|c|c|c|c|c|c|c|c|c|c|}
\hline Plant/Company & Technology & Eff. (\%) & $\begin{array}{l}\mathrm{CO}_{2} \\
\text { conversion }\end{array}$ & $\begin{array}{l}\mathrm{CH}_{4} \\
\text { production } \\
\text { rate }\end{array}$ & $\begin{array}{l}\text { Source of } \\
\text { power }\end{array}$ & $\begin{array}{l}\text { Power input } \\
\text { (MW) }\end{array}$ & $\begin{array}{l}\text { Electricity } \\
\text { consumption } \\
\left(\mathrm{kWh} / \mathrm{kg} \mathrm{CH}_{4}\right)\end{array}$ & $\mathrm{H}_{2}$ source & References \\
\hline ZSW 250-kWel & $\begin{array}{l}\mathrm{CO}_{2} \\
\text { methanation }\end{array}$ & - & - & - & - & - & - & AEL & $\begin{array}{l}\text { Schollenberger et al., } \\
2018\end{array}$ \\
\hline HELMETH & $\begin{array}{l}\mathrm{CO}_{2} \\
\text { methanation }\end{array}$ & $>85$ & - & $1.08-5.42 \mathrm{~m}^{3} / \mathrm{h}$ & - & - & - & SOEC & $\begin{array}{l}14 \text { Ghaib and Ben-Fares, } \\
2018\end{array}$ \\
\hline
\end{tabular}

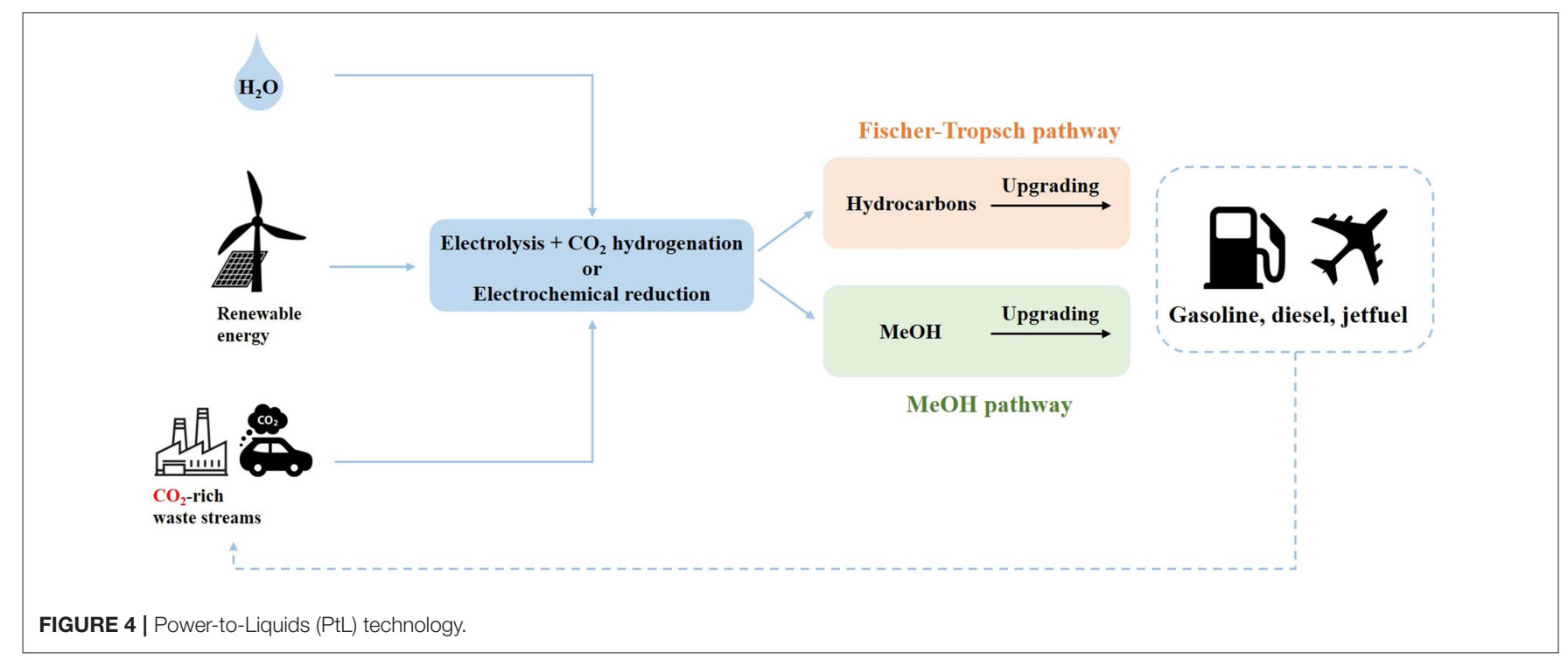

Wei et al. (2017) recently reported the production of gasoline via direct $\mathrm{CO}_{2}$ hydrogenation over a multifunctional $\mathrm{Na}-$ $\mathrm{Fe}_{3} \mathrm{O}_{4} / \mathrm{HZSM}-5$ catalyst. Hydrogenation tests were performed in a fixed-bed reactor at $320^{\circ} \mathrm{C}$ and $3 \mathrm{MPa}$. The catalysts exhibited high selectivity to $\mathrm{C}_{5}-\mathrm{C}_{11}$ of $78 \%$, very low selectivity to methane and $\mathrm{CO}(<10 \%)$ and high stability over $1,000 \mathrm{~h}$ of time on stream (TOS). The authors concluded that the $\mathrm{Fe}_{3} \mathrm{O}_{4}$ sites enabled the RWGS reaction while the zeolite sites favored the oligomerization/aromatization and isomerization. Moreover, the gasoline fraction was composed mainly by isoparaffins and aromatics, having a positive impact on the octane number. The authors further reported that the composition of $\mathrm{C}_{5}-\mathrm{C}_{11}$ could be tuned by using the zeolites with different topologies. HZSM-5 produced $61 \%$ of aromatics in the gasoline fraction while HMCM-22 produced mainly paraffins $(\approx 46 \%)$. Despite the high selectivity of the catalysts, $\mathrm{CO}_{2}$ conversion reached only $22 \%$.

Wang et al. (2016) investigated the production of $\mathrm{C}_{5+}$ isoalkanes, which can be used as gasoline additive, over a $\mathrm{Fe}$ $\mathrm{Zn}$ /zeolite core-shell catalysts prepared by cladding method. Different zeolites (HZSM-5, Hbeta, HY) were investigated in order to verify the influence of their structure in the $\mathrm{CO}_{2}$ hydrogenation reaction at $340^{\circ} \mathrm{C}$ and $5 \mathrm{MPa}$ for $2 \mathrm{~h}$.
Fe-Zn-Zr@HZSM-5-Hbeta double-zeolite shell catalyst with a HZSM-5/Hbeta ratio of 4 showed the highest isoalkanes/total hydrocarbons ratio $(83.1 \%)$. These results were attributed to the synergistic effect of the HZSM-5 that promotes the production i- $\mathrm{C}_{5+}$, with Hbeta zeolites that favors the formation of $\mathrm{i}-\mathrm{C}_{4}$. However, $\mathrm{CO}_{2}$ conversion was very low (around 14\%). The authors also reported that the cladding method used for the preparation of the catalysts was very promising due to its simplicity and low cost, being suitable for use at large scale.

Gao et al. (2017) investigated the performance of a bifunctional catalyst containing partially reducible metal oxides $\left(\mathrm{In}_{2} \mathrm{O}_{3}\right)$ and $\mathrm{H}$-form Zeolite Socony Mobil-5 for the conversion of $\mathrm{CO}_{2}$ into liquid fuels using methanol as intermediate. The catalysts showed a high selectivity gasoline-range hydrocarbons $\left(\mathrm{C}_{5+}\right)$ of $78.6 \%$ along with very low methane selectivity of $1 \%$ for over $150 \mathrm{~h}$ of TOS at $340^{\circ} \mathrm{C}$ and $3 \mathrm{MPa}$. The authors reported that the oxygen vacancies on the $\mathrm{In}_{2} \mathrm{O}_{3}$ activated the $\mathrm{CO}_{2}$ and the $\mathrm{H}_{2}$, producing methanol. Then, a $\mathrm{C}-\mathrm{C}$ coupling occurs in the zeolite pores, converting methanol to $\mathrm{C}_{5+}$ hydrocarbons via a hydrocarbon-pool mechanism. As for all the studies presented up to date on the PtL for gasoline production, $\mathrm{CO}_{2}$ conversion was also very low around $13 \%$. 


\section{Diesel}

Diesel is the main transportation fuel used nowadays for heavy transportation. However, the literature related to $\mathrm{CO}_{2}$ hydrogenation into diesel is very scarce. Recently, Han et al. (2017) proposed a new path for direct $\mathrm{CO}_{2}$ conversion into liquid fuels with renewable hydrogen produced via solar water splitting. $\mathrm{CO}_{2}$ hydrogenation was performed at $300^{\circ} \mathrm{C}$ and 10 bar over a new $\mathrm{Cu}-\mathrm{Fe}$ catalyst, which exhibited excellent catalytic performances with $65 \%$ selectivity to $\mathrm{C}_{5+}$ liquid hydrocarbons and only $2-3 \%$ methane selectivity. The authors reported that the main products of the reaction cover the gasoline $\left(\mathrm{C}_{5}\right.$ $\left.\mathrm{C}_{11}\right)$ and diesel range $\left(\mathrm{C}_{12}-\mathrm{C}_{21}\right)$, the product distribution being very similar to the one observed in CO-FT over iron-based catalysts. The performance of the catalyst was attributed to the swift reduction and selective carburization form of the Hagg iron carbide formed, which is actually the active phase for the production of long-chain hydrocarbons in the $\mathrm{CO}_{2}$ hydrogenation process.

One of the most significant studies is the $\mathrm{CO}_{2}$-to-diesel process developed by Audi in partnership with Sunfire, generating a carbon-neutral diesel fuel, called e-diesel. The process is performed in three main steps. In the first step, $\mathrm{H}_{2}$ is produced from high-temperature water electrolysis using renewable energy. Then, $\mathrm{H}_{2}$ reacts with $\mathrm{CO}_{2}$ (from a biogas facility) under high pressure and high temperature, producing long-chain hydrocarbons, called blue crude. In the final step, the blue crude is refined into e-diesel similarly to the fossil crude oil refining process ${ }^{22}$. The company started the production of ediesel in 2015 and has produced more than three tones of blue crude up to date ${ }^{23}$.

Most of the data reported in the literature about $\mathrm{CO}_{2}$ hydrogenation into diesel-like fuels are actually related to the production of dimethyl ether (DME), which is considered a greener alternative to traditional diesel fuels due to its lower $\mathrm{NO}_{\mathrm{x}}$ emissions, near-zero smoke, less carbon particulates and less engine noise (Wang et al., 2009; Álvarez et al., 2017; Li et al., 2018a). The $\mathrm{MeOH}$ pathway is the main route investigated, being used either in a two-step process in which $\mathrm{MeOH}$ is produced from $\mathrm{CO}_{2}$ hydrogenation in the first step (Equation 10) after what $\mathrm{MeOH}$ is dehydrated in a second step (Equation 12), or in a single-step process, in which both steps are done simultaneously in the same reactor (Wang et al., 2009; Li et al., 2018a).

$$
2 \mathrm{CH}_{3} \mathrm{OH} \rightleftarrows \mathrm{CH}_{3} \mathrm{OCH}_{3}+\mathrm{H}_{2} \mathrm{O} \quad \Delta \mathrm{H}_{298 \mathrm{~K}}=-23.4 \mathrm{~kJ} / \mathrm{mol}(12)
$$

Since $\mathrm{CO}_{2}$ conversion could be thermodynamically limited at low pressures if $\mathrm{MeOH}$ is not continuously removed from the reaction medium, its further conversion into DME in a single step process is preferred (Álvarez et al., 2017). So, studies for catalyst development for this process have focused on the synthesis of bifunctional catalysts capable of performing both reactions (Equations 10 and 12) in a single reactor. In general,

\footnotetext{
${ }^{22}$ https://www.audi-mediacenter.com/en/press-releases/fuel-of-the-futureresearch-facility-in-dresden-produces-first-batch-of-audi-e-diesel-352

${ }^{23}$ https://www.sunfire.de/en/company/news/detail/sunfire-produces-sustainablecrude-oil-alternative
}

catalysts used for each reaction separately are combined in a single bifunctional catalyst, which is synthesized by homogenous mixing of both catalysts, by sequential arrangement or even by homogenous mixing and grinding followed by pelletizing (Roy et al., 2018). It is widely accepted that a simple homogenous mixing results in more performing catalysts, since they maintain their initial properties (Roy et al., 2018). Copper and Zincbased catalysts, for example, have been intensively investigated for the $\mathrm{CO}_{2}$ hydrogenation into methanol (see section $\mathrm{CO}_{2}$ Hydrogenation), first step of the process. $\mathrm{ZnO}$ is responsible for adsorbing $\mathrm{CO}_{2}$ while $\mathrm{Cu}$ adsorbs $\mathrm{H}_{2}$. The second step $(\mathrm{MeOH}$ dehydration) is favored by acid catalysts, such as alumina and zeolites (An et al., 2008). So, An et al. (2008) regrouped the functions of both catalysts in a bifunctional catalyst prepared by a physical mixture of $\mathrm{CuO}-\mathrm{ZnO}-\mathrm{Al}_{2} \mathrm{O}_{3}-\mathrm{ZrO}_{2}$ and $\mathrm{HZSM}-5$ for the $\mathrm{CO}_{2}$ hydrogenation into DME in a single-step process. Reaction temperature and pressure varied between 483 and $543 \mathrm{~K}$ and 2 and $5 \mathrm{MPa}$, respectively. The best catalytic results were obtained at $543 \mathrm{~K}$ and $5 \mathrm{MPa}$ with $\mathrm{CO}_{2}$ conversion of about $27 \%$ and DME selectivity of $15.8 \%$, proving that the authors could successfully synthesize DME from one-step $\mathrm{CO}_{2}$ hydrogenation. Similarly, Wang et al. (2009) investigated the performance of $\mathrm{CuO}-\mathrm{TiO}_{2}-$ $\mathrm{ZrO}_{2} / \mathrm{HZSM}-5$ mixed oxides catalyst for producing DME from $\mathrm{CO}_{2}$ hydrogenation in a one-step process. The catalyst with a $\mathrm{Ti} / \mathrm{Zr}$ ratio of $50 / 50$ presented the best catalytic performance with DME selectivity of $47.5 \%$ (yield $=7.41 \%$ ) and $\mathrm{CO}_{2}$ conversion of $15.6 \%$. The results were attributed to the higher reducibility of this catalyst. Despite the advances on DME synthesis from $\mathrm{CO}_{2}$ hydrogenation over the last few years, low $\mathrm{CO}_{2}$ conversions and low DME selectivity and yield remain a bottleneck of this process.

\section{Jet Fuel}

Since there is no current alternative to fossil jet fuels, the Powerto-Liquids (PtL) technology could represent a huge opportunity to produce a replacement aviation fuel capable of effectively reducing the emissions from the aviation sector (Schmidt et al., 2018). The synthetic paraffinic kerosene produced from this process, for example, can be blended up to $50 \%$ to jet fuels (Schmidt et al., 2016).

There isn't yet a proof-of-concept of an integrated Power-toJetfuel technology. However, the individual steps have already high technological maturity level. Many big industrial actors have been developing this technology. Shell in partnership with other actors created the SOLAR-Jet consortium aiming to demonstrate a carbon-neutral pathway for producing jet fuel using solar energy $^{24}$. The project explored the solar-thermochemical redox cycles between 2011 and 2015 and produced the world's first sample of solar thermochemical kerosene from $\mathrm{H}_{2} \mathrm{O}$ and $\mathrm{CO}_{2}$ at laboratory scale. The Sun-to-Liquid project created in 2016 succeeded the first project and aims to design, fabricate, and experimentally validate a large scale complete solar fuel production plant ${ }^{25}$.

Carbon Engineering's pilot Air to Fuels has successfully produced biocrude from $\mathrm{CO}_{2}$ and water in 2017. In this project,

\footnotetext{
${ }^{24}$ http://www.solar-jet.aero/page/about-solar-jet/objectives.php

${ }^{25}$ https://www.sun-to-liquid.eu/
} 
$\mathrm{CO}_{2}$ is captured from the air, purified and thermo-catalytically reacted with $\mathrm{H}_{2}$ produced from water electrolysis with renewable energy (solar PV), to produce the biocrude ${ }^{26}$. However, their major challenge is upgrading the biocrude into jet fuel. A commercial validation of the integrated technology is expected by 2021.

Carbon Recycling International's George Olah Renewable Methanol Plant in Svartsengi (Iceland) was completed in 2012 and produces 5 million liters of methanol per year. The plant uses hydro and geothermal energy for producing $\mathrm{H}_{2}$ from water electrolysis, which is then reacted with $\mathrm{CO}_{2}$ from flue gases to produce methanol. The methanol (vulcanol) produced can then be blended with gasoline for automobiles or used as intermediate in the production of fuels that could potentially be suitable as synthetic jet fuel (Schmidt et al., 2018).

\section{CONCLUSIONS}

Power-to-X technology has gained increased attention since it tackles issues related to the production of carbon neutral fuels from $\mathrm{CO}_{2}$ and to the storage of renewable energy. The PtX technology includes two main steps: $\mathrm{H}_{2}$ production through water electrolysis using renewable energy and $\mathrm{CO}_{2}$ hydrogenation to chemicals and fuels. Alternatively, $\mathrm{CO}_{2}$ can be directly reduced into useful products via electrochemical reduction also using renewable energy.

Among the different methods for sustainably producing $\mathrm{H}_{2}$, water electrolysis is the main process investigated since it allows the production of high-purity hydrogen from renewable energy and water. AEL, PEM and SOEC are amongst the three most popular technologies for water electrolysis currently being investigated. Among the latter, AEL has the lower investments and maintenance costs and is the most mature, being already commercialized at MW scale. However, coupling it with variable renewable energy could be very challenging due to its long start-up preparation. On the contrary, SOEC is very promising when coupling with renewable energy is considered. Moreover, SOEC systems exhibits a great potential for coupling with exothermic processes as well as for $\mathrm{CO}_{2}$ and water coelectrolysis, but considerable progress is still required to get this technology to a next level. PEM exhibits strategic advantages related to high efficiency and short time response, being the most promising for $\mathrm{PtX}$ applications. The competitiveness of electrolysis in comparison to the other $\mathrm{H}_{2}$ production technologies should increase in the next few years due to the

${ }^{26} \mathrm{http} / / /$ carbonengineering.com/about-a2f/

\section{REFERENCES}

Abate, S., Barbera, K., Giglio, E., Deorsola, F., Bensaid, S., Perathoner, S., et al. (2016). Synthesis, characterization, and activity pattern of $\mathrm{Ni}-\mathrm{Al}$ hydrotalcite catalysts in $\mathrm{CO}_{2}$ methanation. Ind. Eng. Chem. Res. 55, 8299-8308. doi: 10.1021/acs.iecr.6b0 1581

Abdalla, A. M., Hossain, S., Nisfindy, O. B., Azad, A. T., Dawood, M., and Azad, A. K. (2018). Hydrogen production, storage, transportation and key increase in the production of electrolysers as well as on the number of academic and industrial research projects related to this technology. Despite the important advances achieved in the past years, improvements in efficiency as well as cost reduction of electrolysis processes are still required in order to overcome technical and economic barriers to the successful commercialization of $\mathrm{PtX}$.

The second step of the PtX process is the $\mathrm{CO}_{2}$ hydrogenation into chemicals and fuels either via a Fischer-Tropsch pathway or using methanol as intermediate ( $\mathrm{MeOH}$ pathway). The $\mathrm{CO}_{2}$ hydrogenation process is more advanced than the other possible processes, such as $\mathrm{CO}_{2}$ electrochemical reduction, and it may benefit from the existing infrastructure of the classical Fischer-Tropsch process. The main researches on this process focus on the development of more efficient catalysts capable of withstanding the harsh reaction conditions and to selectively produce the desired products. Companies, such as Audi, Carbon Recycling International and ZSW have successfully built and operated PtX commercial plants for the production of methane and methanol.

Alternatively, $\mathrm{CO}_{2}$ can be directed converted into chemicals and fuels through the $\mathrm{CO}_{2}$ electrochemical reduction coupled with renewable energy. Contrarily to the $\mathrm{CO}_{2}$ hydrogenation process, this approach is still being developed at laboratory scale. The main drawbacks that hinders the scale up of this approach is the very low selectivity to the desired products, low efficiency as well as the high overpotentials required. Considerable technical and catalytic advances have yet to be achieved in order to get this technology to a larger scale.

Further development of the PtX technology will mainly require a decrease in the capital costs as well as an improvement of process efficiencies, especially electrolysis, leading to a reduction of the actual high production costs of fuels and chemicals produced through this technology. Validation of the different steps at large scale is also required. Despite the increase in the number of research projects in the area in partnership with industries, data related to the scale-up of the different steps of the technology is still missing. Finally, the integration of these steps to validate the whole PtX process is mandatory to help the technology reach higher technology readiness levels.

\section{AUTHOR CONTRIBUTIONS}

BRV and J-ML both contributed to defining the relevant topics and to the writing of the manuscript.

challenges with applications: a review. Energy Convers. Manag. 165, 602-627. doi: 10.1016/j.enconman.2018.03.088

Alalwan, H. A., Alminshid, A. H., and Aljaafari, H. A. S. (2019). Promising evolution of biofuel generations. Subject review. Renew. Energy Focus 28, 127-139. doi: 10.1016/j.ref.2018.12.006

Albo, J., Alvarez-Guerra, M., Castaño, P., and Irabien, A. (2015). Towards the electrochemical conversion of carbon dioxide into methanol. Green Chem. 17, 2304-2324. doi: 10.1039/c4gc02 $453 b$ 
Álvarez, A., Bansode, A., Urakawa, A., Bavykina, A. V., Wezendonk, T. A., Makkee, M., et al. (2017). Challenges in the greener production of formates/formic acid, methanol, and DME by heterogeneously catalyzed $\mathrm{CO}_{2}$ hydrogenation processes. Chem. Rev. 117, 9804-9838. doi: 10.1021/acs.chemrev.6b00816

An, X., Zuo, Y., Zhang, Q., Wang, D., and Wang, J. (2008). Dimethyl ether synthesis from $\mathrm{CO}_{2}$ hydrogenation on a $\mathrm{CuO}-\mathrm{ZnO}-\mathrm{Al}_{2} \mathrm{O}_{3}$ $\mathrm{ZrO}_{2} / \mathrm{HZSM}-5$ bifunctional catalyst. Ind. Eng. Chem. Res. 47, 6547-6554. doi: $10.1021 /$ ie800777t

Arunkumar, P., Aarthi, U., Rengaraj, S., Cha, S.-W., and Babu, K. S. (2019). Review on solid oxide electrolysis cell: a clean energy strategy for hydrogen generation. Nanomater. Energy 8, 1-73. doi: 10.1680/jnaen.18.00009

Azwar, M. Y., Hussain, M. A., and Abdul-Wahab, A. K. (2014). Development of biohydrogen production by photobiological, fermentation and electrochemical processes: a review. Renew. Sustain. Energy Rev. 31, 158-173. doi: 10.1016/j.rser.2013.11.022

Bacariza, M. C., Maleval, M., Graça, I., Lopes, J. M., and Henriques, C. (2019). Power-to-methane over Ni/zeolites: influence of the framework type. Microporous Mesoporous Mater. 274, 102-112. doi: 10.1016/j.micromeso.2018.07.037

Bailera, M., Lisbona, P., Romeo, L. M., and Espatolero, S. (2017). Power to Gas projects review: lab, pilot and demo plants for storing renewable energy and $\mathrm{CO}_{2}$. Renew. Sustain. Energy Rev. 69, 292-312. doi: 10.1016/j.rser.2016.11.130

Ball, M., and Weeda, M. (2015). The hydrogen economy - Vision or reality? Int. J. Hydrogen Energy 40, 7903-7919. doi: 10.1016/j.ijhydene.2015.04.032

Bandi, A. (1990). Electrochemical Reduction of Carbon Dioxide on Conductive Metallic Oxides. J. Electrochem. Soc. 137, 2157. doi: 10.1149/1.2086903

Baykara, S. Z. (2018). Hydrogen: a brief overview on its sources, production and environmental impact. Int. J. Hydrogen Energy 43, 10605-10614. doi: 10.1016/j.ijhydene.2018.02.022

Bellotti, D., Rivarolo, M., Magistri, L., and Massardo, A. F. (2017). Feasibility study of methanol production plant from hydrogen and captured carbon dioxide. $J$. $\mathrm{CO}_{2}$ Util. 21, 132-138. doi: 10.1016/j.jcou.2017.07.001

Benson, E. E., Kubiak, C. P., Sathrum, A. J., and Smieja, J. M. (2009). Electrocatalytic and homogeneous approaches to conversion of $\mathrm{CO}_{2}$ to liquid fuels. Chem. Soc. Rev. 38, 89-99. doi: 10.1039/b804323j

Berkeley, L. (2017). Sunfire SOEC steam electrolysis module for Salzgitter Flachstahl. Fuel Cells Bull. 2017, 12. doi: 10.1016/s1464-2859(17)30269-9

Bessarabov, D., and Millet, P. (2018). "The PEM water electrolysis plant," in PEM Water Electrolysis, B. Pollet (San Diego, CA: Academic Press), 1-31.

BP Energy Economics (2018). BP Energy Outlook 2018 Edition.

Buttler, A., and Spliethoff, H. (2018). Current status of water electrolysis for energy storage, grid balancing and sector coupling via power-to-gas and power-to-liquids: a review. Renew. Sustain. Energy Rev. 82, 2440-2454. doi: 10.1016/j.rser.2017.09.003

Caravaca, A., De Lucas-Consuegra, A., Calcerrada, A. B., Lobato, J., Valverde, J. L., and Dorado, F. (2013). From biomass to pure hydrogen: electrochemical reforming of bio-ethanol in a PEM electrolyser. Appl. Catal. B Environ. 134-135, 302-309. doi: 10.1016/j.apcatb.2013.01.033

Carmo, M., Fritz, D. L., Mergel, J., and Stolten, D. (2013). A comprehensive review on PEM water electrolysis. Int. J. Hydrogen Energy 38, 4901-4934. doi: 10.1016/j.ijhydene.2013.01.151

Chan, F. L., Altinkaya, G., Fung, N., and Tanksale, A. (2018). Low temperature hydrogenation of carbon dioxide into formaldehyde in liquid media. Catal. Today 309, 242-247. doi: 10.1016/j.cattod.2017.06.012

Chen, R., and Liu, Y. (2018). "Catalysis of $\mathrm{CO}_{2}$ electroreduction," in Electrochemical Reduction of Carbon Dioxide-Fundamentals and Technologies, eds J. Qiao, Y. Liu, and J. Zhang (Oakville: CRC Press), 155-227. doi: 10.1201/b20177-5

Chi, J., and Yu, H. (2018). Water electrolysis based on renewable energy for hydrogen production. Chinese J. Catal. 39, 390-394. doi: $10.1016 /$ S1872-2067(17)62949-8

Child, M., Bogdanov, D., and Breyer, C. (2018). The role of storage technologies for the transition to a $100 \%$ renewable energy system in Europe. Energy Procedia 155, 44-60. doi: 10.1016/j.egypro.2018.11.067

Chourashiya, M. G., and Urakawa, A. (2017). Solution combustion synthesis of highly dispersible and dispersed iridium oxide as an anode catalyst in PEM water electrolysis. J. Mater. Chem. A 5, 4774-4778. doi: 10.1039/ c6ta11047a
Core, R. (2018). Hydrogen for Energy Storage and Transportation at Scale. Available online at: https://www.energy.gov/sites/prod/files/2018/08/f54/fcto-h2-scalekickoff-2018-7-del-core.pdf. (accessed December 23, 2018).

Corma, A., Torre, O., De Renz, M., and Villandier, N. (2011). Production of High-Quality Diesel from Biomass Waste Products. Angew. Chemie Int. Ed. 50, 2375-2378. doi: 10.1002/anie.201007508

Coutanceau, C., Baranton, S., and Audichon, T. (2018). "Hydrogen production from water electrolysis," in Hydrogen Electrochemical Production, ed B. Pollet (San Diego, CA: Academic Press), 17-62. doi: 10.1016/b978-0-12-811250-2.00003-0

Dang, S., Yang, H., Gao, P., Wang, H., Li, X., Wei, W., et al. (2018). A review of research progress on heterogeneous catalysts for methanol synthesis from carbon dioxide hydrogenation. Catal. Today 330, 61-75. doi: 10.1016/j.cattod.2018.04.021

Das, P., and Tiwari, P. (2018). The effect of slow pyrolysis on the conversion of packaging waste plastics (PE and PP) into fuel. Waste Manag. 79, 615-624. doi: 10.1016/j.wasman.2018.08.021

Datta, M. K., Kadakia, K., Velikokhatnyi, O. I., Jampani, P. H., Chung, S. J., Poston, J. A., et al. (2013). High performance robust F-doped tin oxide based oxygen evolution electro-catalysts for PEM based water electrolysis. J. Mater. Chem. A 1, 4026-4037. doi: 10.1039/c3ta01458d

Di Giovanni, C., Reyes-Carmona, Á., Coursier, A., Nowak, S., Grenèche, J. M., Lecoq, H., et al. (2016). Low-Cost Nanostructured Iron Sulfide Electrocatalysts for PEM Water Electrolysis. ACS Catal. 6, 2626-2631. doi: $10.1021 /$ acscatal.5b02443

Dincer, I., and Zamfirescu, C. (2016). "Hydrogen production by electrical energy," in Sustainable Hydrogen Production, eds I. Dincer and C. Zamfirescu (Cambridge: Elsevier), 99-161.

Dulal, H. B., Brodnig, G., and Onoriose, C. G. (2011). Climate change mitigation in the transport sector through urban planning: a review. Habitat Int. 35, 494-500. doi: 10.1016/j.habitatint.2011.02.001

Egbue, O., and Long, S. (2012). Barriers to widespread adoption of electric vehicles: an analysis of consumer attitudes and perceptions. Energy Policy 48, 717-729. doi: 10.1016/j.enpol.2012.06.009

Ferreira-Aparicio, P., Benito, M. J., and Sanz, J. L. (2005). New trends in reforming technologies: from hydrogen industrial plants to multifuel microreformers. Catal. Rev. 47, 491-588. doi: 10.1080/01614940500364958

Filonenko, G. A., Van Putten, R., Schulpen, E. N., Hensen, E. J. M., and Pidko, E. A. (2014). Highly efficient reversible hydrogenation of carbon dioxide to formates using a ruthenium PNP-pincer catalyst. ChemCatChem 6, 1526-1530. doi: $10.1002 /$ cctc. 201402119

Fortis, B. C. (2018). Clean Growth Pathway to 2050 Contents. Fortis, BC.

Frese, K. W. (1991). Electrochemical reduction of $\mathrm{CO}_{2}$ at intentionally oxidized copper electrodes. J. Electrochem. Soc. 138, 3338-3344.

Frontera, P., Macario, A., Ferraro, M., and Antonucci, P. (2017). Supported catalysts for $\mathrm{CO}_{2}$ methanation: a review. Catalysts 7, 1-28. doi: $10.3390 /$ catal7020059

Galadima, A., and Muraza, O. (2015). Waste to liquid fuels: potency, progress and challenges. Int. J. Energy Res. 39, 1451-1478. doi: 10.1002/er.3360

Gao, P., Li, S., Bu, X., Dang, S., Liu, Z., Wang, H., et al. (2017). Direct conversion of $\mathrm{CO}_{2}$ into liquid fuels with high selectivity over a bifunctional catalyst. Nat. Chem. 9, 1-6. doi: 10.1038/nchem.2794

Ghaib, K., and Ben-Fares, F. Z. (2018). Power-to-Methane: a state-of-the-art review. Renew. Sustain. Energy Rev. 81, 433-446. doi: 10.1016/j.rser.2017.08.004

Goeppert, A., Czaun, M., Jones, J. P., Surya Prakash, G. K., and Olah, G. A. (2014). Recycling of carbon dioxide to methanol and derived products-closing the loop. Chem. Soc. Rev. 43, 7995-8048. doi: 10.1039/c4cs00122b

Götz, M., Lefebvre, J., Mörs, F., McDaniel Koch, A., Graf, F., Bajohr, S., et al. (2016). Renewable Power-to-Gas: a technological and economic review. Renew. Energy 85, 1371-1390. doi: 10.1016/j.renene.2015.07.066

Gunasekar Hariyanandam, G., Park, K., Jung, K. D., and Yoon, S. (2016). Recent developments in the catalytic hydrogenation of $\mathrm{CO}_{2}$ to formic acid/formate using heterogeneous catalysts. Inorg. Chem. Front. 3, 882-895. doi: 10.1039/c5qi00231a

Gutierrez-Guerra, N., Jimenez-Vazquez, M., Serrano-Ruiz, J. C., Valverde, J. L., and de Lucas-Consuegra, A. (2015). Electrochemical reforming vs. catalytic reforming of ethanol: a process energy analysis for hydrogen production. Chem. Eng. Process. Process Intensif. 95, 9-16. doi: 10.1016/j.cep.2015.05.008 
Han, Y., Jeong, Y., Park, H., Young, W., Hye, Y., Hee, S., et al. (2017). Carbon dioxide Fischer-Tropsch synthesis: a new path to carbon-neutral fuels. Appl. Catal. B Environ. 202, 605-610. doi: 10.1016/j.apcatb.2016.09.072

Hank, C., Gelpke, S., Schnabl, A., White, R. J., Full, J., Wiebe, N., et al. (2018). Economics \& carbon dioxide avoidance cost of methanol production based on renewable hydrogen and recycled carbon dioxide - power-to-methanol. Sustain. Energy Fuels 2, 1244-1261. doi: 10.1039/C8SE00032H

Hansen, J. B. (2015). Solid oxide electrolysis-a key enabling technology for sustainable energy scenarios. Faraday Discuss. 182, 9-48. doi: $10.1039 / \mathrm{c} 5 \mathrm{fd} 90071 \mathrm{a}$

Hao, C., Wang, S., Li, M., Kang, L., and Ma, X. (2011). Hydrogenation of $\mathrm{CO}_{2}$ to formic acid on supported ruthenium catalysts. Catal. Today 160, 184-190. doi: 10.1016/j.cattod.2010.05.034

Hara, K., Kudo, A., and Sakata, T. (1995). High Efficiency Electrochemical Reduction of Carbon Dioxide under High Pressure on a Gas Diffusion Electrode Containing Pt Catalysts. J. Electrochem. Soc. 142, 57-59.

He, L., Lin, Q., Liu, Y., and Huang, Y. (2014). Unique catalysis of Ni$\mathrm{Al}$ hydrotalcite derived catalyst in $\mathrm{CO}_{2}$ methanation: cooperative effect between $\mathrm{Ni}$ nanoparticles and a basic support. J. Energy Chem. 23, 587-592. doi: 10.1016/S2095-4956(14)60144-3

Heim, L. E., Konnerth, H., and Prechtl, M. H. G. (2016). The prospecting shortcut to an old molecule: formaldehyde synthesis at low temperature in solution. ChemSusChem 9, 2905-2907. doi: 10.1002/cssc.201601043

Heim, L. E., Konnerth, H., and Prechtl, M. H. G. (2017). Future perspectives for formaldehyde: pathways for reductive synthesis and energy storage. Green Chem. 19, 2347-2355. doi: 10.1039/c6gc03093a

Hori, Y. (2008). "Electrochemical $\mathrm{CO}_{2}$ reduction on metal electrodes," in Modern Aspects of Electrochemistry 42, ed C. G. Vayenas (New York, NY: SpringerVerlag), 89-189. doi: 10.1007/978-0-387-49489-0

Hori, Y., Wakebe, H. H. I., Tsukamoto, T., and Koga, O. (1994). Electrocatalytic process of $\mathrm{CO}$ selectivity in electrochemical reduction of $\mathrm{CO}_{2}$ at metal electrodes in aqueous media. Electrochim. Acta 39, 1833-1839.

Hu, H., Fan, Y., and Liu, H. (2008). Hydrogen production using singlechamber membrane-free microbial electrolysis cells. Water Res. 42, 4172-4178. doi: 10.1016/j.watres.2008.06.015

Huang, B. (2018). Recycling of lithium-ion batteries: recent advances and perspectives. J. Power Sources J. 399, 274-286. doi: 10.1016/j.jpowsour.2018.07.116

Huang, Y., Deng, Y., Handoko, A. D., Goh, G. K. L., and Yeo, B. S. (2018). Rational design of sulfur-doped copper catalysts for the selective electroreduction of carbon dioxide to formate. ChemSusChem 11, 320-326. doi: $10.1002 /$ cssc. 201701314

Hwang, H., Yeon, Y. J., Lee, S., Choe, H., Jang, M. G., Cho, D. H., et al. (2015). Electro-biocatalytic production of formate from carbon dioxide using an oxygen-stable whole cell biocatalyst. Bioresour. Technol. 185, 35-39. doi: 10.1016/j.biortech.2015.02.086

Jadhav, S. G., Vaidya, P. D., Bhanage, B. M., and Joshi, J. B. (2014). Catalytic carbon dioxide hydrogenation to methanol: a review of recent studies. Chem. Eng. Res. Des. 92, 2557-2567. doi: 10.1016/j.cherd.2014.03.005

Jia, F., Yu, X., and Zhang, L. (2014). Enhanced selectivity for the electrochemical reduction of $\mathrm{CO}_{2}$ to alcohols in aqueous solution with nanostructured $\mathrm{Cu}-\mathrm{Au}$ alloy as catalyst. J. Power Sources 252, 85-89. doi: 10.1016/j.jpowsour.2013.12.002

Kaneco, S., Katsumata, H., Suzuki, T., and Ohta, K. (2006). Electrochemical reduction of $\mathrm{CO}_{2}$ to methane at the $\mathrm{Cu}$ electrode in methanol with sodium supporting salts and its comparison with other alkaline salts. Energy Fuels 20, 409-414. doi: 10.1021/ef050274d

Kaneco, S., Yabuuchi, M., Katsumata, H., Suzuki, T., and Ohta, K. (2002). Electrochemical reduction of $\mathrm{CO}_{2}$ to methane in methanol at low temperature. Fuel Chem. Div. Prepr. 47, 71-72.

Karelovic, A., and Ruiz, P. (2012). $\mathrm{CO}_{2}$ hydrogenation at low temperature over $\mathrm{Rh} /-\mathrm{Al}_{2} \mathrm{O}_{3}$ catalysts: effect of the metal particle size on catalytic performances and reaction mechanism. Appl. Catal. B Environ. 113-114, 237-249. doi: 10.1016/j.apcatb.2011.11.043

Kassargy, C., Awad, S., Burnens, G., Kahine, K., and Tazerout, M. (2018). Gasoline and diesel-like fuel production by continuous catalytic pyrolysis of waste polyethylene and polypropylene mixtures over USY zeolite. Fuel 224, 764-773. doi: 10.1016/j.fuel.2018.03.113
Kondratenko, E. V., Mul, G., Baltrusaitis, J., Larrazábal, G. O., and Pérez-Ramírez, J. (2013). Status and perspectives of $\mathrm{CO}_{2}$ conversion into fuels and chemicals by catalytic, photocatalytic and electrocatalytic processes. Energy Environ. Sci. 6, 3112-3135. doi: 10.1039/c3ee41272e

Kortlever, R., Balemans, C., Kwon, Y., and Koper, M. T. M. (2015). Electrochemical $\mathrm{CO}_{2}$ reduction to formic acid on a Pd-based formic acid oxidation catalyst. Catal. Today 244, 58-62. doi: 10.1016/j.cattod.2014.08.001

Kourkoumpas, D. S., Papadimou, E., Atsonios, K., Karellas, S., Grammelis, P., and Kakaras, E. (2016). Implementation of the Power to Methanol concept by using $\mathrm{CO}_{2}$ from lignite power plants: techno-economic investigation. Int. J. Hydrogen Energy 41, 16674-16687. doi: 10.1016/j.ijhydene.2016.07.100

Koytsoumpa, E. I., Bergins, C., and Kakaras, E. (2018). The $\mathrm{CO}_{2}$ economy: review of $\mathrm{CO}_{2}$ capture and reuse technologies. J. Supercrit. Fluids 132, 3-16. doi: 10.1016/j.supflu.2017.07.029

Kuhl, K. P., Hatsukade, T., Cave, E. R., Abram, D. N., Kibsgaard, J., and Jaramillo, T. F. (2014). Electrocatalytic Conversion of Carbon Dioxide to Methane and Methanol on Transition Metal Surfaces. J. Am. Chem. Soc. 136, 14107-14113. doi: 10.1021/ja505791r

Kumar, B., Atla, V., Brian, J. P., Kumari, S., Nguyen, T. Q., Sunkara, M., et al. (2017). Reduced $\mathrm{SnO}_{2}$ porous nanowires with a high density of grain boundaries as catalysts for efficient electrochemical $\mathrm{CO}_{2}$-into- $\mathrm{HCOOH}$ conversion. Angew. Chem. Int. Ed. 56, 3645-3649. doi: 10.1002/anie.201612194

Lambert, M. (2018). Power-to-Gas: Linking Electricity and Gas in a Decarbonising World?

Lavoie, J.-M. (2014). Review on dry reforming of methane, a potentially more environmentally-friendly approach to the increasing natural gas exploitation. Front. Chem. 2, 1-17. doi: 10.3389/fchem.2014.00081

Lazkano, I., Nøstbakken, L., and Pelli, M. (2017). From fossil fuels to renewables: the role of electricity storage. Eur. Econ. Rev. 99, 113-129. doi: 10.1016/j.euroecorev.2017.03.013

Le, M., Ren, M., Zhang, Z., Sprunger, P. T., Kurtz, R. L., and Flake, J. C. (2011). Electrochemical reduction of $\mathrm{CO}_{2}$ to $\mathrm{CH}_{3} \mathrm{OH}$ at copper oxide surfaces. J. Electrochem. Soc. 158, 45-49. doi: 10.1149/1.3561636

Le, Q. A. T., Kim, H. G., and Kim, Y. H. (2018). Electrochemical synthesis of formic acid from $\mathrm{CO}_{2}$ catalyzed by Shewanella oneidensis MR-1 whole-cell biocatalyst. Enzyme Microb. Technol. 116, 1-5. doi: 10.1016/j.enzmictec.2018.05.005

Lee, D., Kim, D., and Kim, S.-W. (2001). Selective formation of formaldehyde from carbon dioxide and hydrogen over $\mathrm{PtCu} / \mathrm{SiO}_{2}$. Appl. Organomet. Chem. 15, 148-150. doi: 10.1002/1099-0739(200102)15:2<148::aid-aoc104>3.0.co;2-n

Li, J., Wang, L., Cao, Y., Zhang, C., He, P., and Li, H. (2018a). Recent advances on the reduction of $\mathrm{CO}_{2}$ to important $\mathrm{C}_{2+}$ oxygenated chemicals and fuels. Chinese J. Chem. Eng. 26, 2266-2279. doi: 10.1016/j.cjche.2018. 07.008

Li, S., Yan, R., Wu, G., Xie, K., and Cheng, J. (2013). Composite oxygen electrode LSM-BCZYZ impregnated with $\mathrm{Co} 3 \mathrm{O} 4$ nanoparticles for steam electrolysis in a proton-conducting solid oxide electrolyzer. Int. J. Hydrogen Energy 38, 14943-14951. doi: 10.1016/j.ijhydene.2013.09.082

Li, W., Wang, H., Jiang, X., Zhu, J., Liu, Z., and Guo, X. (2018b). A short review of recent advances in $\mathrm{CO}_{2}$ hydrogenation to hydrocarbons over heterogeneous catalysts. RSC Adv. 8, 7651-7669. doi: 10.1039/C7RA13546G

Liu, C., Xie, J. H., Tian, G. L., Li, W., and Zhou, Q. L. (2015). Highly efficient hydrogenation of carbon dioxide to formate catalyzed by iridium(iii) complexes of imine-diphosphine ligands. Chem. Sci. 6, 2928-2931. doi: $10.1039 / \mathrm{c} 5 \mathrm{sc} 00248 \mathrm{f}$

Machado, A. S. R., Nunes, A. V. M., and da Ponte, M. N. (2018). Carbon dioxide utilization-Electrochemical reduction to fuels and synthesis of polycarbonates. J. Supercrit. Fluids 134, 150-156. doi: 10.1016/j.supflu.2017.12.023

Malik, M. I., Omar, Z., Atieh, M., and Abussaud, B. (2016). Electrochemical reduction of $\mathrm{CO}_{2}$ to methanol over MWCNTs impregnated with $\mathrm{Cu}_{2} \mathrm{O}$. Chem. Eng. Sci. 152, 468-477. doi: 10.1016/j.ces.2016.06.035

Manthiram, K., Beberwyck, B. J., and Alivisatos, A. P. (2014). Enhanced electrochemical methanation of carbon dioxide with a dispersible nanoscale copper catalyst. J. Am. Chem. Soc. 136, 13319-13325. doi: 10.1021/ ja5065284

Martinson, C. A., Van Schoor, G., Uren, K. R., and Bessarabov, D. (2014). Characterisation of a PEM electrolyser using the current interrupt method. Int. J. Hydrogen Energy 39, 20865-20878. doi: 10.1016/j.ijhydene.2014.09.153 
Ministère des Transports du Québec (2015). Propelling Québec Forward with Electricity-Transportation Electrification Action Plan 2015-2020. Gouvernement du Québec, Ministère des Transports du Québec.

Moçoteguy, P., and Brisse, A. (2013). A review and comprehensive analysis of degradation mechanisms of solid oxide electrolysis cells. Int. J. Hydrogen Energy 38, 15887-15902. doi: 10.1016/j.ijhydene.2013.09.045

Munshi, P., Main, A. D., Linehan, J. C., Tai, C. C., and Jessop, P. G. (2002). Hydrogenation of carbon dioxide catalyzed by ruthenium trimethylphosphine complexes: the accelerating effect of certain alcohols and amines. J. Am. Chem. Soc. 124, 7963-7971. doi: 10.1021/ja0167856

Mura, M. G., De Luca, L., Giacomelli, G., and Porcheddu, A. (2012). Formic acid: a promising bio-renewable feedstock for fine chemicals. Adv. Synth. Catal. 354, 3180-3186. doi: 10.1002/adsc.201200748

Nakata, K., Ozaki, T., Terashima, C., Fujishima, A., and Einaga, Y. (2014). High-yield electrochemical production of formaldehyde from $\mathrm{CO}_{2}$ and seawater. Angew. Chem. Int. Ed. 53, 871-874. doi: 10.1002/anie. 201308657

Ogawa, T., Takeuchi, M., and Kajikawa, Y. (2018). Analysis of trends and emerging technologies in water electrolysis research based on a computational method: a comparison with fuel cell research. Sustainability 10, 1-24. doi: $10.3390 /$ su10020478

Ohmori, T., Tachikawa, K., Tsuji, K., and Anzai, K. (2007). Nickel oxide water electrolysis diaphragm fabricated by a novel method. Int. J. Hydrogen Energy 32, 5094-5097. doi: 10.1016/j.ijhydene.2007.07.055

Olah, G. A., Goeppert, A., and Prakash, G. K. S. (2009). Chemical recycling of carbon dioxide to methanol and dimethyl ether: from greenhouse gas to renewable, environmentally carbon neutral fuels and synthetic hydrocarbons. J. Org. Chem. 74, 487-498. doi: 10.1021/jo801260f

Olah, G. A., and Prakash, G. K. S. (2010). Electrolysis of Carbon Dioxide in Aqueous Media to Carbon Monoxide and Hydrogen for Production of Methanol. Washington, DC.

Onishi, N., Laurenczy, G., Beller, M., and Himeda, Y. (2018). Recent progress for reversible homogeneous catalytic hydrogen storage in formic acid and in methanol. Coord. Chem. Rev. 373, 317-332. doi: 10.1016/j.ccr.2017.11.021

Overland, I. (2016). Energy: the missing link in globalization. Energy Res. Soc. Sci. 14, 122-130. doi: 10.1016/j.erss.2016.01.009

Pérez-Fortes, M., Schöneberger, J. C., Boulamanti, A., and Tzimas, E. (2016). Methanol synthesis using captured $\mathrm{CO}_{2}$ as raw material: technoeconomic and environmental assessment. Appl. Energy 161, 718-732. doi: 10.1016/j.apenergy.2015.07.067

Peterson, A. A., and Norskov, J. K. (2012). Activity descriptors for $\mathrm{CO}_{2}$ electroreduction to methane on transition-metal catalysts. J. Phys. Chem. Lett. 3, 251-258.

Qin, Z., Zhou, Y., Jiang, Y., Liu, Z., and Ji, H. (2017). "Recent advances in heterogeneous catalytic hydrogenation of $\mathrm{CO}$ to methane," in New Advances in Hydrogenation Processes-Fundamentals and Applications, M. T. Ravanchi (Rijeka: Intech), 57-82. Available online at: https://cdn.intechopen.com/pdfs/ 52449.pdf

Qu, J., Zhang, X., Wang, Y., and Xie, C. (2005). Electrochemical reduction of $\mathrm{CO}_{2}$ on $\mathrm{RuO}_{2} / \mathrm{TiO}_{2}$ nanotubes composite modified Pt electrode. Electrochim. Acta 50, 3576-3580. doi: 10.1016/j.electacta.2004.11.061

Quak, H., Nesterova, N., and Van Rooijen, T. (2016). Possibilities and barriers for using electric-powered vehicles in city logistics practice. Transp. Res. Procedia 12, 157-169. doi: 10.1016/j.trpro.2016.02.055

Rashid, M. M., Al Mesfer, M. K., Naseem, H., and Danish, M. (2015). Hydrogen production by water electrolysis: a review of alkaline water electrolysis, PEM water electrolysis and high temperature water electrolysis. Int. J. Eng. Adv. Technol. 4, 80-93.

Rego de Vasconcelos, B., and Lavoie, J.-M. (2018). Is dry reforming the solution to reduce natural gas carbon footprint? Int. J. Energy Prod. Manag. 3, 44-56. doi: 10.2495/eq-v3-n1-44-56

Reis Machado, A. S., and Nunes da Ponte, M. (2018). $\mathrm{CO}_{2}$ capture and electrochemical conversion. Curr. Opin. Green Sustain. Chem. 11, 86-90. doi: 10.1016/j.cogsc.2018.05.009

Rihko-Struckmann, L. K., Peschel, A., Hanke-Rauschenbach, R., and Sundmacher, K. (2010). Assessment of methanol synthesis utilizing exhaust $\mathrm{CO}_{2}$ for chemical storage of electrical energy. Ind. Eng. Chem. Res. 49, 11073-11078. doi: $10.1021 / \mathrm{ie} 100508 \mathrm{w}$
Roy, S., Cherevotan, A., and Peter, S. C. (2018). Thermochemical $\mathrm{CO}_{2}$ hydrogenation to single carbon products: scientific and technological challenges. ACS Energy Lett. 3, 1938-1966. doi: 10.1021/acsenergylett.8b00740

Sapountzi, F. M., Gracia, J. M., Weststrate, C. J. K. J., Fredriksson, H. O. A., and Niemantsverdriet, J. W. H. (2017). Electrocatalysts for the generation of hydrogen, oxygen and synthesis gas. Prog. Energy Combust. Sci. 58, 1-35. doi: 10.1016/j.pecs.2016.09.001

Schaaf, T., Grünig, J., Schuster, M. R., Rothenfluh, T., and Orth, A. (2014). Methanation of $\mathrm{CO}_{2}$-storage of renewable energy in a gas distribution system. Energy. Sustain. Soc. 4, 1-14. doi: 10.1186/s13705-014-0029-1

Schildhauer, T. J., and Biollaz, S. M. A. (2016). Synthetic Natural Gas from Coal, Dry Biomass, and Power-to-Gas Applications. Hoboken, NJ: John Wiley \& Sons, Inc.

Schmidt, O., Gambhir, A., Staffell, I., Hawkes, A., Nelson, J., and Few, S. (2017). Future cost and performance of water electrolysis: an expert elicitation study. Int. J. Hydrogen Energy 42, 30470-30492. doi: 10.1016/j.ijhydene.2017.10.045

Schmidt, P., Batteiger, V., Roth, A., Weindorf, W., and Raksha, T. (2018). Powerto-liquids as renewable fuel option for aviation: a review. Chemie Ing. Tech. 90, 127-140. doi: 10.1002/cite.201700129

Schmidt, P., Weindorf, W., Roth, A., Batteiger, V., and Riegel, F. (2016). Powerto-Liquids-Potentials and Perspectives for the Future Supply of Renewable Aviation Fuel. Dessau-Roßlau: German Environment Agency.

Schollenberger, D., Bajohr, S., Gruber, M., Reimert, R., and Kolb, T. (2018). Scale-up of innovative honeycomb reactors for power-to-gas applications-the project store \& go. Chem. Ing. Tech. 90, 696-702. doi: 10.1002/cite.201700139

Singh, A. K., Singh, S., and Kumar, A. (2016). Hydrogen energy future with formic acid: a renewable chemical hydrogen storage system. Catal. Sci. Technol. 6, 12-40. doi: 10.1039/c5cy01276g

Stangeland, K., Kalai, D., Li, H., and Yu, Z. (2017). $\mathrm{CO}_{2}$ methanation: the effect of catalysts and reaction conditions. Energy Procedia 105, 2022-2027. doi: 10.1016/j.egypro.2017.03.577

Steinmann, W. (2017). Thermo-mechanical concepts for bulk energy storage. Renew. Sustain. Energy Rev. 75, 205-219. doi: 10.1016/j.rser.2016.10.065

Sternberg, A., and Bardow, A. (2015). Power-to-what?-environmental assessment of energy storage systems. Energy Environ. Sci. 8, 389-400. doi: 10.1039/C4EE03051F

Su, J., Yang, L., Lu, M., and Lin, H. (2015). Highly efficient hydrogen storage system based on ammonium bicarbonate/formate redox equilibrium over palladium nanocatalysts. ChemSusChem 8, 813-816. doi: 10.1002/cssc.201403251

Swalus, C., Jacquemin, M., Poleunis, C., Bertrand, P., and Ruiz, P. (2012). $\mathrm{CO}_{2}$ methanation on $\mathrm{Rh} / \gamma-\mathrm{Al}_{2} \mathrm{O}_{3}$ catalyst at low temperature: "In situ" supply of hydrogen by Ni/activated carbon catalyst. Appl. Catal. B Environ. 125, 41-50. doi: 10.1016/j.apcatb.2012.05.019

Tanaka, R., Yamashita, M., and Nozaki, K. (2009). Catalytic hydrogenation of carbon dioxide using Ir (III)-pincer complexes. J. Am. Chem. Soc. Commun. 131, 14168-14169. doi: 10.1021/ja903574e

Tervo, E., Agbim, K., Deangelis, F., Hernandez, J., Kim, H. K., and Odukomaiya, A. (2018). An economic analysis of residential photovoltaic systems with lithium ion battery storage in the United States. Renew. Sustain. Energy Rev. 94, 1057-1066. doi: 10.1016/j.rser.2018.06.055

The European Commission Directorate General for Energy (2013). World Energy Scenarios. London: World Energy Council.

Thiruvengadam, A., Besch, M., Padmanaban, V., Pradhan, S., and Demirgok, B. (2018). Natural gas vehicles in heavy-duty transportation-a review. Energy Policy 122, 253-259. doi: 10.1016/j.enpol.2018.07.052

Thorin, E. (2014). "Basics of energy," in Reference Module in Earth Systems and Environmental Sciences (Elsevier Inc.), 1-2.

Umegaki, T., Enomoto, Y., and Kojima, Y. (2016). Metallic ruthenium nanoparticles for hydrogenation of supercritical carbon dioxide. Catal. Sci. Technol. 6, 409-412. doi: 10.1039/c5cy00994d

Varela, A. S., Kroschel, M., Reier, T., and Strasser, P. (2016). Controlling the selectivity of $\mathrm{CO}_{2}$ electroreduction on copper: the effect of the electrolyte concentration and the importance of the local pH. Catal. Today 260, 8-13. doi: 10.1016/j.cattod.2015.06.009

Vassileva, I., and Campillo, J. (2017). Adoption barriers for electric vehicles: experiences from early adopters in Sweden. Energy 120, 632-641. doi: 10.1016/j.energy.2016.11.119

Vázquez, F. V., Koponen, J., Ruuskanen, V., Bajamundi, C., Kosonen, A., Simell, P., et al. (2018). Power-to-X technology using renewable electricity 
and carbon dioxide from ambient air: SOLETAIR proof-of-concept and improved process concept. J. $\mathrm{CO}_{2}$ Util. 28, 235-246. doi: 10.1016/J.JCOU.2018. 09.026

Voitic, G., Nestl, S., Lammer, M., Wagner, J., and Hacker, V. (2015). Pressurized hydrogen production by fixed-bed chemical looping. Appl. Energy 157, 399-407. doi: 10.1016/j.apenergy.2015.03.095

Wang, S., Mao, D., Guo, X., Wu, G., and Lu, G. (2009). Dimethyl ether synthesis via $\mathrm{CO}_{2}$ hydrogenation over $\mathrm{CuO}-\mathrm{TiO}_{2}-\mathrm{ZrO}_{2} / \mathrm{HZSM}-5$ bifunctional catalysts. Catal. Commun. 10, 1367-1370. doi: 10.1016/j.catcom.2009. 02.001

Wang, W. H., Himeda, Y., Muckerman, J. T., Manbeck, G. F., and Fujita, E. (2015). $\mathrm{CO}_{2}$ hydrogenation to formate and methanol as an alternative to photo- and electrochemical $\mathrm{CO}_{2}$ reduction. Chem. Rev. 115, 12936-12973. doi: $10.1021 /$ acs.chemrev.5b00197

Wang, X., Yang, G., Zhang, J., Chen, S., Wu, Y., Zhang, Q., et al. (2016). Synthesis of isoalkanes over a core (Fe- Zn-Zr)-shell (zeolite) catalyst by $\mathrm{CO}_{2}$ hydrogenation. Chem. Commun. 52, 7352-7355. doi: 10.1039/C6CC0 1965J

Watanabe, M., Shibata, M., and Katoh, A. (1991). Design of alloy electrocatalysts for reduction-improved energy efficiency, selectivity, and reaction rate for the $\mathrm{CO}_{2}$ electroreduction on $\mathrm{Cu}$ alloy electrodes. J. Electroanal. Chem. Interfacial Electrochem. 305, 319-328.

Wei, J., Yao, R., Wen, Z., Fang, C., Guo, L., Xu, H., et al. (2017). Directly converting $\mathrm{CO}_{2}$ into a gasoline fuel. Nat. Commun. 8, 1-8. doi: 10.1038/ncomms1 5174
Zeng, K., and Zhang, D. (2010). Recent progress in alkaline water electrolysis for hydrogen production and applications. Prog. Energy Combust. Sci. 36, 307-326. doi: $10.1016 /$ j.pecs.2009.11.002

Zhang, B., and Zhang, J. (2017). Rational design of Cu-based electrocatalysts for electrochemical reduction of carbon dioxide. J. Energy Chem. 26, 1050-1066. doi: 10.1016/j.jechem.2017.10.011

Zhang, L., Zhao, Z.-J., and Gong, J. (2017). Nanostructured materials for heterogeneous electrocatalytic $\mathrm{CO}_{2}$ reduction and related reaction mechanisms. Angew. Chem. Int. Ed. 56, 11326-11353. doi: $10.1002 /$ anie. 201612214

Zhang, W., Wang, S., Zhao, Y., and Ma, X. (2018). Hydrogenation of $\mathrm{CO}_{2}$ to formic acid catalyzed by heterogeneous $\mathrm{Ru}-\mathrm{PPh}_{3} / \mathrm{Al}_{2} \mathrm{O}_{3}$ catalysts. Fuel Process. Technol. 178, 98-103. doi: 10.1016/j.fuproc.2018.05.024

Conflict of Interest Statement: The authors declare that the research was conducted in the absence of any commercial or financial relationships that could be construed as a potential conflict of interest.

Copyright (๔ 2019 Rego de Vasconcelos and Lavoie. This is an open-access article distributed under the terms of the Creative Commons Attribution License (CC BY). The use, distribution or reproduction in other forums is permitted, provided the original author(s) and the copyright owner(s) are credited and that the original publication in this journal is cited, in accordance with accepted academic practice. No use, distribution or reproduction is permitted which does not comply with these terms. 